\title{
Adsorption, Thermodynamic and Quantum Chemical Studies of 1-hexyl-3-methylimidazolium Based Ionic Liquids as Corrosion Inhibitors for Mild Steel in $\mathbf{H C l}$
}

\author{
Motsie E. Mashuga 1,2, Lukman O. Olasunkanmi 1,2,3, Abolanle S. Adekunle ${ }^{1,2,3}$, \\ Sasikumar Yesudass ${ }^{1}$, Mwadham M. Kabanda ${ }^{1,2}$ and Eno E. Ebenso ${ }^{1,2, *}$
}

1 Department of Chemistry, School of Mathematics and Physical Sciences, Faculty of Agriculture, Science and Technology, North-West University (Mafikeng Campus) Private Bag X2046, Mmabatho 2735, South Africa; E-Mails: motsiemashuga@yahoo.com (M.E.M.); waleolasunkanmi@gmail.com (L.O.O.); sadekpreto@gmail.com (A.S.A.); sasikumar.phd@gmail.com (S.Y.); Mwadham.Kabanda@nwu.ac.za (M.M.K.)

2 Material Science Innovation and Modelling (MaSIM) Research Focus Area, Faculty of Agriculture, Science and Technology, North-West University (Mafikeng Campus) Private Bag X2046, Mmabatho 2735, South Africa

3 Department of Chemistry, Faculty of Science, Obafemi Awolowo University, Ile-Ife 220005, Nigeria

* Author to whom correspondence should be addressed; E-Mail: Eno.Ebenso@nwu.ac.za; Tel.: +27-183-892-113 (ext. 2050 or 2051); Fax: +27-183-892-052.

Academic Editor: Parama Chakraborty Banerjee

Received: 18 March 2015 / Accepted: 10 June 2015 / Published: 17 June 2015

\begin{abstract}
The inhibition of mild steel corrosion in $1 \mathrm{M} \mathrm{HCl}$ solution by some ionic liquids (ILs) namely, 1-hexyl-3-methylimidazolium trifluoromethanesulfonate [HMIM][TfO], 1-hexyl-3-methylimidazolium tetrafluoroborate [HMIM][BF4], 1-hexyl-3-methylimidazolium hexafluorophosphate [HMIM][PF6], and 1-hexyl-3-methylimidazolium iodide [HMIM][I] was investigated using electrochemical measurements, spectroscopic analyses and quantum chemical calculations. All the ILs showed appreciably high inhibition efficiency. At $303 \mathrm{~K}$, the results of electrochemical measurements indicated that the studied ILs are mixed-type inhibitors. The adsorption studies showed that all the four ILs adsorb spontaneously on steel surface with $[\mathrm{HMIM}][\mathrm{TfO}],\left[\mathrm{HMIM}^{2}\left[\mathrm{BF}_{4}\right]\right.$ and $[\mathrm{HMIM}][\mathrm{I}]$ obeying Langmuir adsorption isotherm, while $[\mathrm{HMIM}]\left[\mathrm{PF}_{6}\right]$ conformed better with Temkin adsorption isotherm. Spectroscopic analyses suggested the formation of Fe/ILs complexes. Some quantum chemical parameters were calculated to corroborate experimental results.
\end{abstract}


Keywords: corrosion inhibition; mild steel; ionic liquid; adsorption; quantum chemical calculations

\section{Introduction}

Mild steel is extensively used in industries for various applications including construction of tanks, gas cylinders, pipelines, heat exchangers among others due to its excellent mechanical strength and relatively low cost. Many industrial processes involve the use of acid solutions and other chemical substances that constitute aggressive media for steel corrosion [1-5]. As a result, researches on corrosion inhibition of mild steel are of considerable interest due to the importance of steel in industrial and/or structural applications.

Various organic compounds containing nitrogen, oxygen, phosphorus and/or sulfur heteroatoms, and/or $\pi$-electron systems have been reported as inhibitors of metal corrosion in different aggressive media [1-11]. These groups of atoms or bonds facilitate electronic interactions between organic corrosion inhibitors and metal surface thereby aid adsorption of the inhibitors onto metal surface [9]. Researches in the field of corrosion inhibitors in the recent years have been directed towards the design and quest for "green" corrosion inhibitors due to the new generation of environmental regulations requirements for the replacement of toxic chemicals with the so-called "green chemicals" [12-16]. The quest for eco-friendly compounds as corrosion inhibitors has shifted research focus to exploring potential application of ILs as corrosion inhibitors in the past few years [17-23].

Ionic liquids (ILs) are materials that compose of entirely ions, and large organic cations and organic/inorganic anions and demonstrate melting points below $100{ }^{\circ} \mathrm{C}[24,25]$. They possess various distinct properties such as high thermal and chemical stability, low vapour pressure, large electrochemical window, tuneable/designer nature, and excellent solvent properties for a range of polar and nonpolar compounds [25]. The low vapour pressure characteristic makes ILs to be easy to regenerate and reuse without appreciable loss into the environment [25-27]. This makes them to be classified as benign compounds to the environment. Imidazolium-based ILs have been reported to possess efficient inhibition properties against corrosion of metals and alloys in acidic environments [22,28-31]. Despite their good anti-corrosion potential, corrosion inhibition properties of some imidazolium-based ILs have not yet been explored.

The objective of the present work is to investigate the inhibition properties of four 1-hexyl-3-methylimidazolium (HMIM) based ionic liquids (ILs) namely, 1-hexyl-3-methylimidazolium trifluoromethanesulfonate [HMIM][TfO], 1-hexyl-3-methylimidazolium tetrafluoroburate [HMIM][BF4], 1-hexyl-3-methylimidazolium iodide [HMIM][I] and 1-hexyl-3-methylimidazolium hexafluorophosphate [HMIM][PF 6$]$ for mild steel corrosion in $1 \mathrm{M} \mathrm{HCl}$. To the best of our knowledge, the ILs used in this work have not been considered for exactly the same study in the past. The studied ILs have the same cations, [HMIM] but different anions. Therefore, the effect of different anions on the corrosion inhibition activities of the four ILs will be investigated. 


\section{Results and Discussion}

\subsection{Electrochemical Measurements}

\subsubsection{Potentiodynamic Polarization (PDP)}

Potentiodynamic polarization curves for mild steel in $1 \mathrm{M} \mathrm{HCl}$ without and with different concentrations (100-500 ppm) of the studied ionic liquid inhibitors are presented in Figure 1. The values of corrosion potential $\left(E_{\text {corr }}\right)$ and kinetic parameters such as corrosion current density $\left(i_{\text {corr }}\right)$, anodic and cathodic Tafel slopes $\left(\beta_{\mathrm{a}}\right.$ and $\left.\beta_{\mathrm{c}}\right)$ and polarization resistance $\left(R_{\mathrm{P}}\right)$ obtained from the polarization curves are presented in Table 1. The results as presented in Figure 1 show that in the presence of the inhibitors, the curves are shifted to the lower current regions. This observation confirms the corrosion inhibition property of the ILs. There is a slight difference in the values of $E_{\text {corr }}$ between the inhibitor containing systems and the blank system. However, it is important to state that the $E_{\text {corr }}$ values for the inhibitor containing systems shift essentially towards the cathodic region relative to that of the blank as shown in Figure 1. The maximum shift in $E_{\text {corr }}$ value relative to the $E_{\text {corr }}$ of the blank is $71 \mathrm{mV}$. Since an inhibitor can only be regarded as anodic or cathodic type when the displacement in $E_{\text {corr }}$ is greater than $85 \mathrm{mV}$ [32,33], the studied ILs behave as mixed-type inhibitors. That is, they inhibit both the anodic dissolution and cathodic hydrogen evolution reaction. The slight change in the values of $\beta_{\mathrm{a}}$ and $\beta_{\mathrm{c}}$ upon addition of the inhibitors when compared with the blank suggests that the ILs get adsorbed onto the metal surface without affecting the mechanism of the mild steel corrosion in the acid [34]. The higher values of $\beta_{c}$ compared to the values of $\beta_{a}$ suggests predominant cathodic reactions and hence, the inhibitors will have more effect on the cathodic reaction sites [34]. It can be observed that the current density $\left(i_{\text {corr }}\right)$ decreases as the concentration of inhibitors increases, which confirms the corrosion inhibition activity of the studied ILs. The inhibition efficiency increases with increase in concentration of the inhibitors with a maximum value of $81.16 \%$ obtained for $[\mathrm{HMIM}][\mathrm{TfO}]$ as shown in Table 1 . The plots of $\% I E$ obtained from the potentiodynamic polarization study versus concentration of inhibitors are shown in Figure 2.

The $\% I E$ at 500 ppm follows the order [HMIM][TfO] $>[\mathrm{HMIM}][\mathrm{I}]>[\mathrm{HMIM}]\left[\mathrm{BF}_{4}\right]>[\mathrm{HMIM}]\left[\mathrm{PF}_{6}\right]$. It is clear from the results in Table 1 and Figure 2 that the trend of inhibition strength of the studied ILs is not easy to generalize for the range of concentrations of the ILs considered in this work. For instance, [HMIM][I] exhibits the highest inhibition activity at $100 \mathrm{ppm}(58.25 \%)$, while [HMIM] $\left[\mathrm{BF}_{4}\right]$ shows the highest inhibition potential at $200 \mathrm{ppm}$ (71.32\%). This dissension in the trend of inhibition efficiency with change in concentration of ILs is not impossible and can be attributed to selfaggregation of the ILs at their critical aggregation concentrations (cac). Similar trend has been reported for ionic liquids with imidazolium and pyridinium cations but without possible reasons [31]. Our suggestion is in line with the fact that ILs and surfactants are known to undergo self-aggregation and micellization at some characteristic concentrations [35-42]. Association into aggregates by ILs as well as micelle formation by surfactants are affected by a number of factors, which include alkyl chain, nature of counterions and interactions with water [35-37]. Since the studied ILs have different anions, they are expected to have different critical aggregate concentration (cac) values, which could have effect on their inhibition ability. Surface active compounds such as ILs and surfactants have been 
reported to exhibit higher corrosion inhibition potential in their aggregated or micelle forms $[38,39]$. There are some reports on the relationship between corrosion inhibition efficiency and surface activities [39-42]. Though, these reports are common for surfactant inhibitors with special attention on effect of alkyl chain length, the possibility of such relationship for ILs inhibitors having with common cations but different anions, such as the case in the present work cannot be ruled out. It is evident that further studies need to be carried out on the ability of the studied ILs to undergo association into aggregates in aqueous acidic medium for better understanding of the variation in their $\% I E$ at various concentrations. The higher \%IE obtained for [HMIM][TfO] (at $500 \mathrm{ppm}$ ) compared with other ILs considered in this study can be attributed to the presence of more than one heteroatoms with high electronegativity $(\mathrm{S}, \mathrm{O})$ in its anions which enhances its adsorption on the surface of the mild steel thus improving its inhibition efficiency [43].
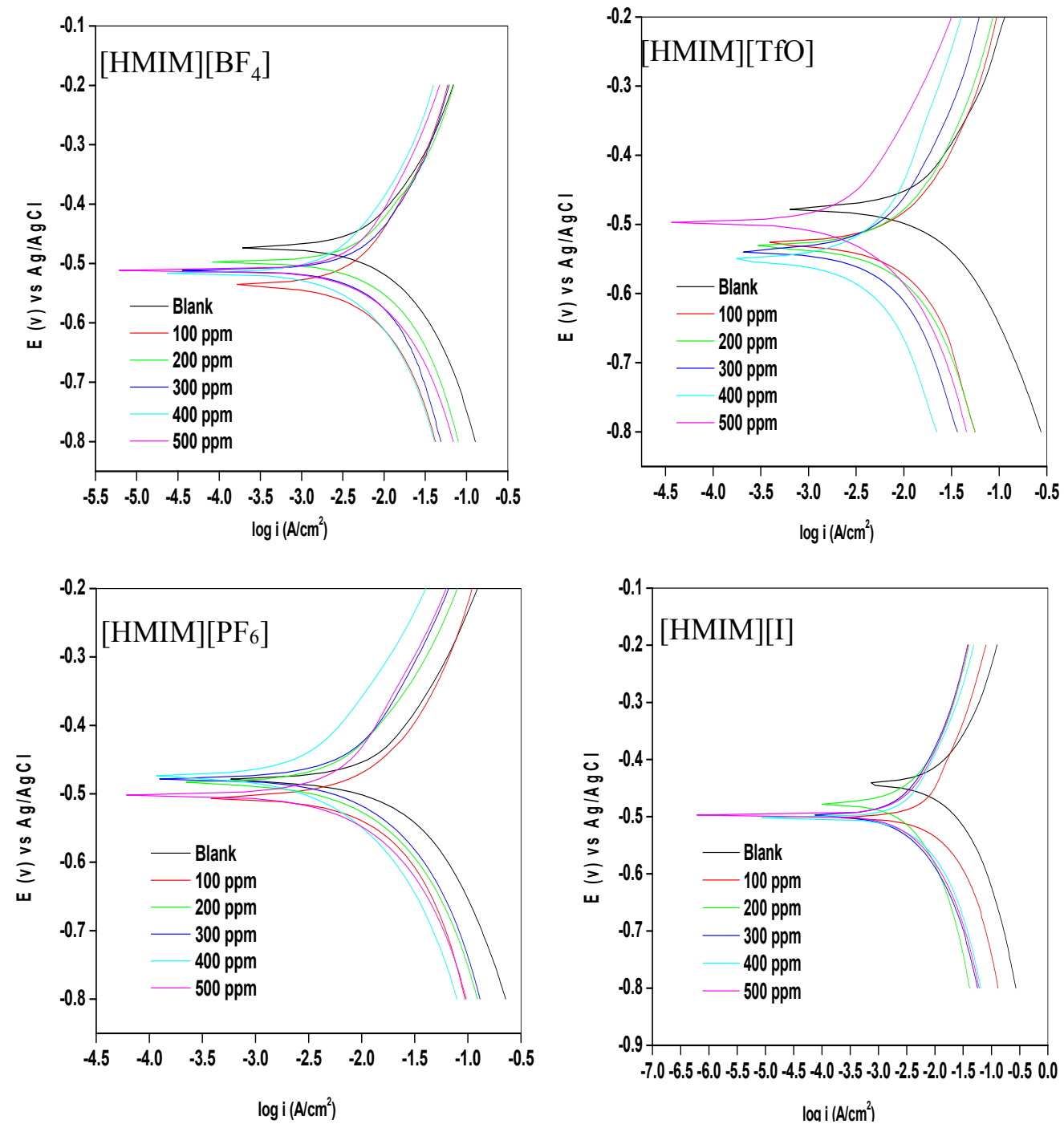

Figure 1. Potentiodynamic polarization curves for mild steel in $1 \mathrm{M} \mathrm{HCl}$ without and with different concentrations of [HMIM][BF4], [HMIM][TfO], [HMIM][PF6] and [HMIM][I]. 


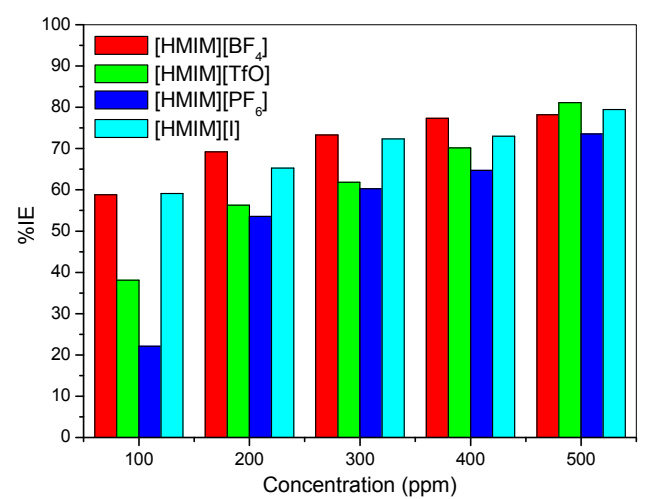

Figure 2. Inhibition efficiency from the potentiodynamic polarization technique versus concentration of inhibitors.

Table 1. Kinetic parameters obtained from potentiodynamic polarization study of mild steel in $1 \mathrm{M} \mathrm{HCl}$ without and with different concentrations of [HMIM][BF4], [HMIM][TfO], [HMIM][PF6] and [HMIM][I].

\begin{tabular}{|c|c|c|c|c|c|c|}
\hline $\begin{array}{c}\text { Concentration } \\
(\mathbf{p p m})\end{array}$ & $\begin{array}{l}-E_{\text {corr }} \\
(\mathrm{mV})\end{array}$ & $\begin{array}{c}i_{\text {corr }} \\
\left(\mathrm{mA} / \mathbf{c m}^{2}\right)\end{array}$ & $\begin{array}{c}R_{\mathrm{p}} \\
\left(\mathrm{Oh} / \mathbf{c m}^{2}\right)\end{array}$ & $\begin{array}{c}\beta_{\mathbf{a}} \\
(\mathbf{m V} / \mathbf{d e c})\end{array}$ & $\begin{array}{c}\boldsymbol{\beta}_{\mathrm{c}} \\
(\mathrm{mV} / \mathrm{dec})\end{array}$ & $\% I E_{\mathrm{PDP}}$ \\
\hline Blank & 480 & 9.45 & 1.04 & 123 & 184 & - \\
\hline \multicolumn{7}{|l|}{$[\mathrm{HMIM}]\left[\mathrm{BF}_{4}\right]$} \\
\hline 100 & 537 & 3.89 & 4.88 & 198 & 220 & 58.84 \\
\hline 200 & 498 & 2.91 & 2.13 & 101 & 141 & 69.21 \\
\hline 300 & 512 & 2.52 & 2.17 & 100 & 126 & 73.33 \\
\hline 400 & 516 & 2.14 & 5.79 & 160 & 178 & 77.35 \\
\hline 500 & 512 & 2.06 & 2.37 & 79 & 142 & 78.20 \\
\hline \multicolumn{7}{|l|}{ [HMIM][TfO] } \\
\hline 100 & 527 & 5.85 & 2.13 & 162 & 178 & 38.10 \\
\hline 200 & 532 & 4.13 & 2.07 & 129 & 153 & 56.30 \\
\hline 300 & 538 & 3.60 & 3.62 & 161 & 186 & 61.90 \\
\hline 400 & 551 & 2.82 & 6.20 & 195 & 206 & 70.16 \\
\hline 500 & 497 & 1.78 & 4.94 & 114 & 178 & 81.16 \\
\hline \multicolumn{7}{|l|}{$[\mathrm{HMIM}]\left[\mathrm{PF}_{6}\right]$} \\
\hline 100 & 505 & 7.36 & 1.57 & 159 & 168 & 22.12 \\
\hline 200 & 484 & 4.39 & 1.84 & 114 & 164 & 53.54 \\
\hline 300 & 478 & 3.75 & 1.42 & 89 & 138 & 60.32 \\
\hline 400 & 502 & 3.34 & 1.74 & 81 & 165 & 64.76 \\
\hline 500 & 475 & 2.50 & 4.26 & 124 & 198 & 73.54 \\
\hline \multicolumn{7}{|l|}{$[\mathrm{HMIM}][\mathrm{I}]$} \\
\hline 100 & 507 & 3.86 & 3.02 & 133 & 202 & 59.15 \\
\hline 200 & 477 & 3.28 & 3.88 & 145 & 117 & 65.29 \\
\hline 300 & 498 & 2.62 & 5.56 & 173 & 193 & 72.38 \\
\hline 400 & 502 & 2.55 & 3.82 & 118 & 190 & 73.02 \\
\hline 500 & 497 & 1.94 & 3.90 & 120 & 146 & 79.47 \\
\hline
\end{tabular}




\subsubsection{Electrochemical Impedance Spectroscopy (EIS)}

The impedance method provides information about the kinetics of the electrode processes as well as the surface properties of the investigated systems. The shape of the impedance gives information about the mechanism of corrosion inhibition [44]. EIS measurements were carried out to study the corrosion of mild steel in $1 \mathrm{M} \mathrm{HCl}$ in the absence and presence of different concentrations of [HMIM][BF4], [HMIM][TfO], [HMIM][PF6] and [HMIM][I] ILs. The Nyquist and Bode plots were obtained and are presented in Figures 3 and 4 respectively. Each spectrum in the Nyquist plots is characterized by a single full semicircle. It can be observed that the diameter of semicircle for the inhibitor containing systems have large capacitive loop with low frequency dispersion (inductive arc). Normally the anodic adsorbed intermediates that control the anodic reactions are the main factors behind the inductive arc $[45,46]$. The increasing diameter of capacitive loop obtained with increasing concentration of the ILs showed the inhibition of mild steel corrosion by the ILs. The curve fitting and simulation of the Nyquist and Bode plots was carried out by using the $R(R Q)$ equivalent model circuit of the form in Figure 5. The kinetic parameters obtained from the fitting are presented in Table 2. The depression in Nyquist semicircles is a feature for solid electrodes and often referred to as frequency dispersion and attributed to the roughness and inhomogeneity of the solid electrode [47]. In this behaviour of solid electrodes, the parallel network charge transfer resistance-double layer capacitance is established where an inhibitor is present. For the description of a frequency-independent phase shift between an applied alternating current (ac) potential and its current response, a constant phase element (CPE) is used. The values of $C_{\mathrm{dl}}$ (double-layer capacitance) were calculated using the equation below:

$$
C_{\mathrm{dl}}=\left(Y_{0} R_{\mathrm{ct}}^{1-\mathrm{n}}\right)^{1 / \mathrm{n}}
$$

where $Y_{0}$ is the CPE (constant phase capacitance) constant, $R_{\text {ct }}$ the resistance of charge transfer and $n$ is a CPE exponent which can be used as a gauge of the heterogeneity or roughness of the surface [33].
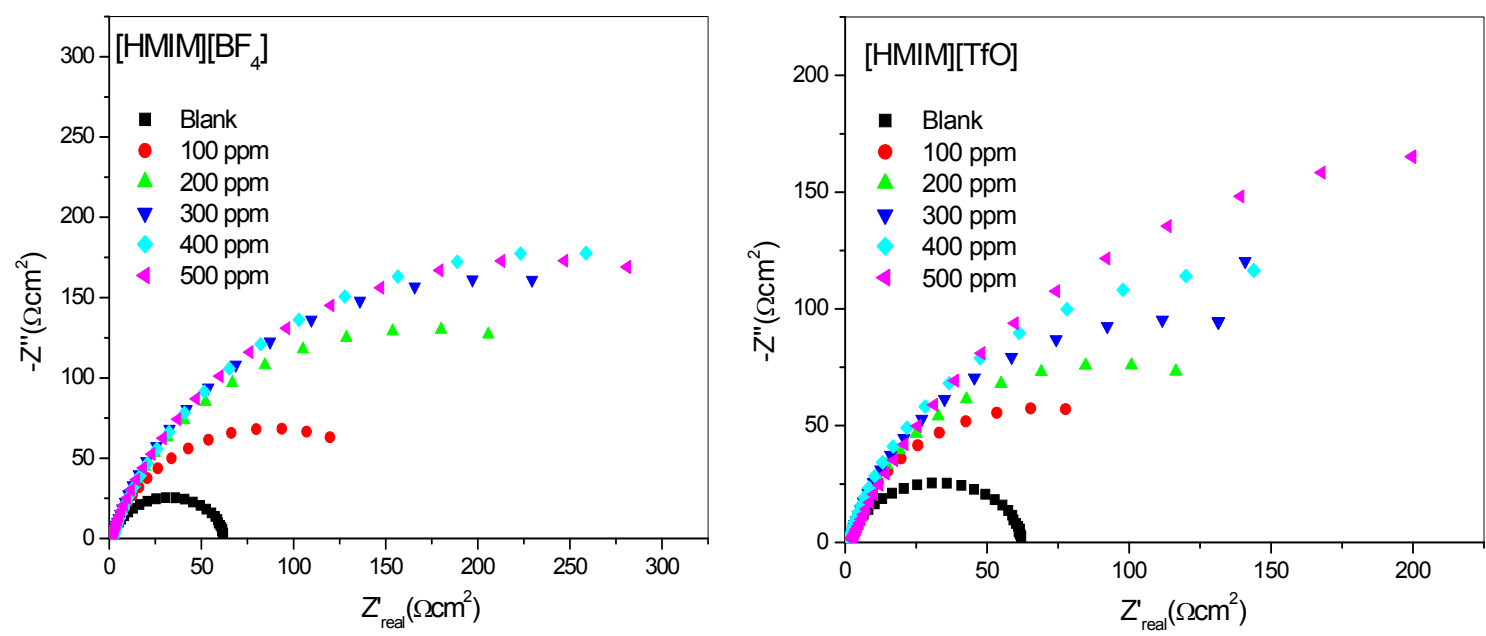

Figure 3. Cont. 

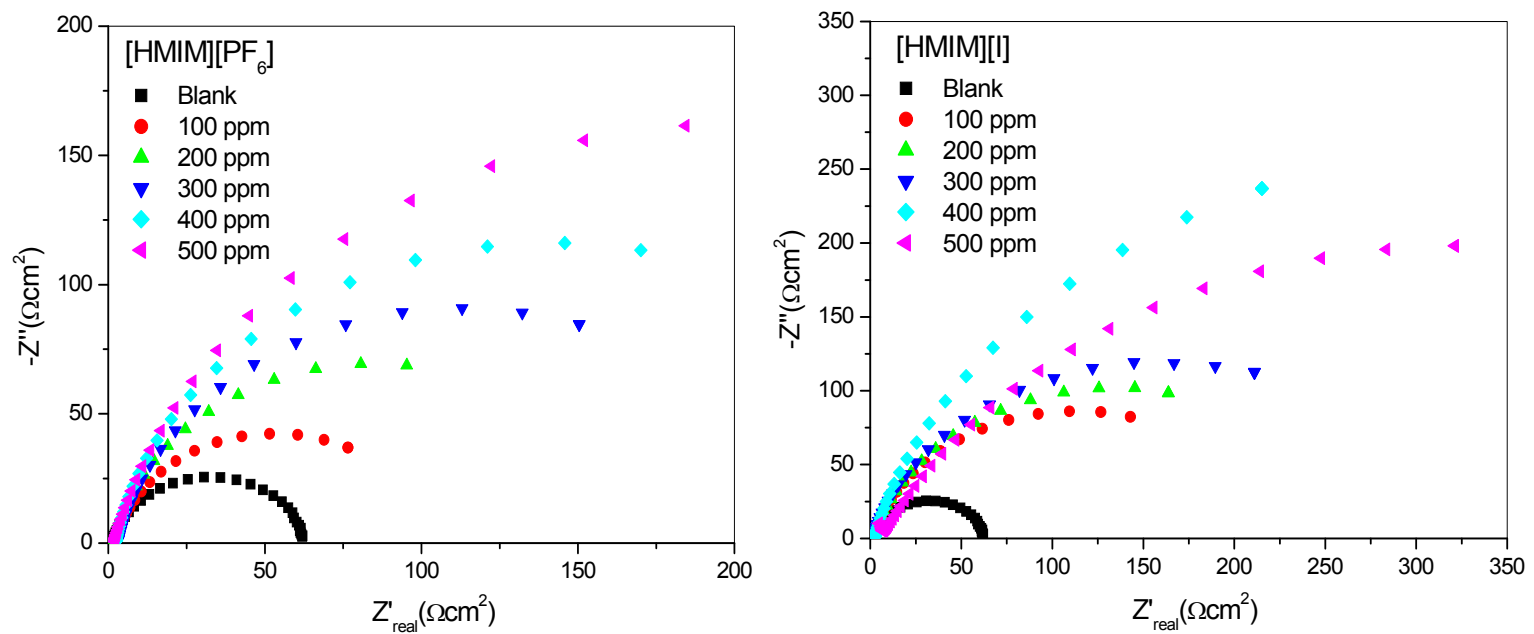

Figure 3. Nyquist plots for mild steel in $1 \mathrm{M} \mathrm{HCl}$ without and with different concentrations of [HMIM][BF4], [HMIM][TfO], [HMIM][PF6] and [HMIM][I].
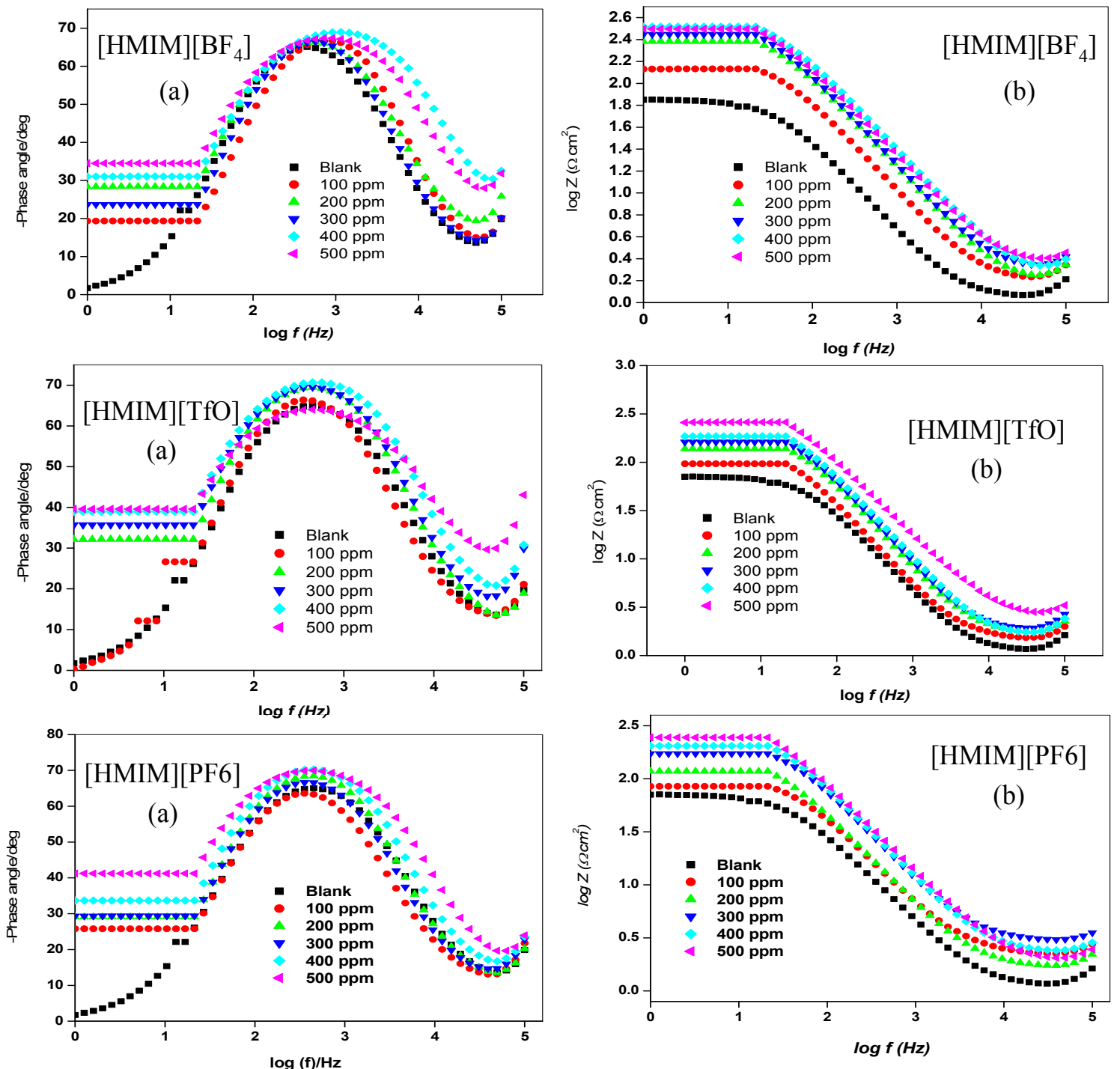

Figure 4. Cont. 

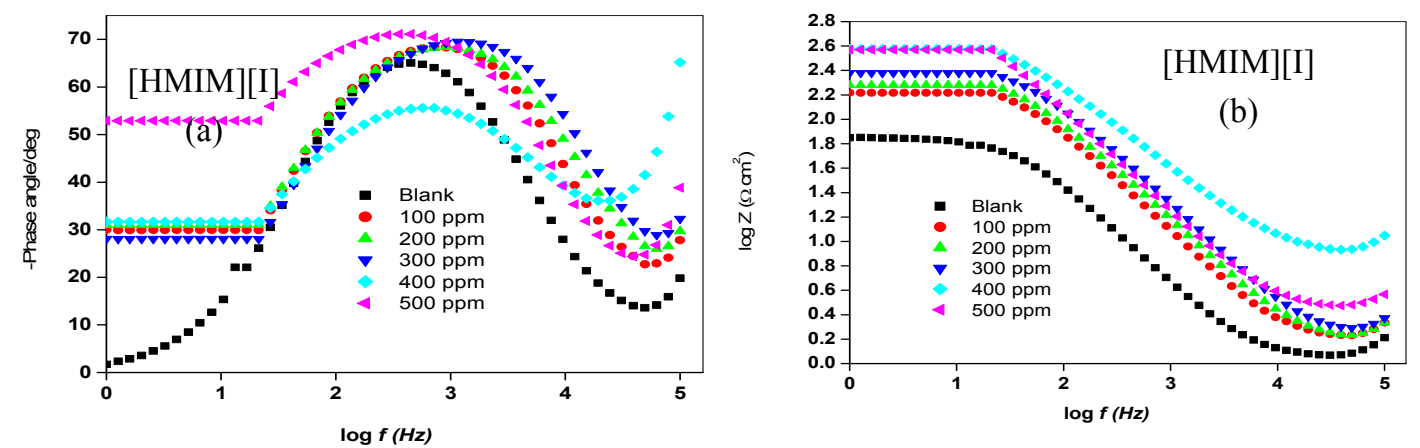

Figure 4. Bode plots (a) Phase angle $v s . \log \mathrm{f}$ and (b) $\log \mathrm{Z} v s . \log \mathrm{f}$ for mild steel in $1 \mathrm{M}$ $\mathrm{HCl}$ without and with different concentrations of [HMIM][BF4], [HMIM][TfO], [HMIM][PF6] and [HMIM][I].

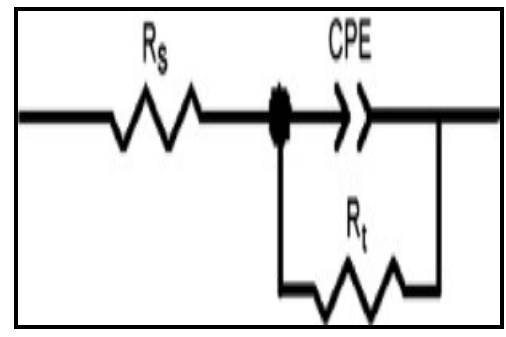

Figure 5. The equivalent model circuit of the impedance spectra.

Table 2. Kinetic parameters obtained from the electrochemical impedance spectroscopy study on mild steel in $1 \mathrm{M} \mathrm{HCl}$ without and with different concentrations of [HMIM][BF4], [HMIM][TfO], [HMIM][PF6] and [HMIM][I].

\begin{tabular}{|c|c|c|c|c|}
\hline Concentration. (ppm) & $\operatorname{Rs}\left(\Omega \mathbf{c m}^{2}\right)$ & $C_{d l}\left(\mu F \cdot \mathbf{c m}^{-2}\right)$ & $R_{\mathrm{ct}}\left(\Omega \mathrm{cm}^{2}\right)$ & $\% I E_{\mathrm{EIS}}$ \\
\hline Blank & 1.25 & 42.10 & 63.30 & - \\
\hline \multicolumn{5}{|c|}{ [HMIM][BF 4} \\
\hline 100 & 1.80 & 19.12 & 146.30 & 56.70 \\
\hline 200 & 1.74 & 10.24 & 220.70 & 71.32 \\
\hline 300 & 2.19 & 9.92 & 254.40 & 75.32 \\
\hline 400 & 2.50 & 8.19 & 280.00 & 77.39 \\
\hline 500 & 2.07 & 7.01 & 294.90 & 78.54 \\
\hline \multicolumn{5}{|c|}{ [HMIM][TfO] } \\
\hline 100 & 1.53 & 39.20 & 105.50 & 40.00 \\
\hline 200 & 1.96 & 30.43 & 147.40 & 57.06 \\
\hline 300 & 2.01 & 22.52 & 176.10 & 64.05 \\
\hline 400 & 1.90 & 20.10 & 203.30 & 68.86 \\
\hline 500 & 1.91 & 10.60 & 314.6 & 79.88 \\
\hline \multicolumn{5}{|c|}{ [HMIM][PF } \\
\hline 100 & 2.39 & 30.02 & 79.60 & 20.48 \\
\hline 200 & 1.62 & 25.23 & 127.70 & 50.43 \\
\hline 300 & 3.20 & 16.93 & 162.70 & 61.09 \\
\hline 400 & 2.49 & 15.78 & 192.70 & 67.15 \\
\hline 500 & 2.10 & 14.29 & 222.50 & 71.55 \\
\hline
\end{tabular}


Table 2. Cont.

\begin{tabular}{|c|c|c|c|c|}
\hline Concentration. (ppm) & $\operatorname{Rs}_{\mathrm{S}}\left(\Omega \mathrm{cm}^{2}\right)$ & $C_{d l}\left(\mu F \cdot \mathbf{c m}^{-2}\right)$ & $R_{\text {ct }}\left(\Omega \mathrm{cm}^{2}\right)$ & $\% I E_{\mathrm{EIS}}$ \\
\hline \multicolumn{5}{|c|}{ [HMIM][I] } \\
\hline 100 & 1.71 & 14.73 & 151.60 & 58.25 \\
\hline 200 & 1.71 & 11.90 & 173.10 & 63.43 \\
\hline 300 & 1.87 & 8.35 & 216.50 & 70.76 \\
\hline 400 & 2.75 & 11.91 & 278.90 & 77.30 \\
\hline 500 & 7.95 & 5.21 & 313.50 & 79.81 \\
\hline
\end{tabular}

The results in Table 2 show that the $R_{\mathrm{ct}}$ values in the presence of inhibitors are generally higher than that of the blank system. This can be attributed to the adsorption of ionic liquid inhibitors to mild steel surface thereby minimizing direct or continuous exposure of the mild steel to the corrosive medium. There is also an increase in $R_{\mathrm{ct}}$ values with increasing concentration of the inhibitors. This can be attributed to increase in number of molecules of ILs that bind to the mild steel surface. On the other hand, the $C_{\mathrm{dl}}$ values decreased accordingly except at $500 \mathrm{ppm}$ concentration of [HMIM][BF4] and [HMIM][I] where a small increase in the $C_{\mathrm{dl}}$ value was noticed. The decrease in $C_{\mathrm{dl}}$ values at the metal/solution interface with increasing inhibitor concentration can result from the decrease in local dielectric constant which indicates that the inhibitors were adsorbed on the surface at both anodic and cathodic sites [48]. Decrease in $C_{\mathrm{dl}}$ values could also mean an increase in the thickness of a protective layer at mild steel electrode surface, therefore enhancing the corrosion resistance of the steel. The thickness of the protective layer $(d)$ is related to $\mathrm{C}_{\mathrm{dl}}$ according to the equation:

$$
C_{\mathrm{d} 1}=\frac{\varepsilon \varepsilon_{0}}{d}
$$

where, $\varepsilon$ is the dielectric constant of the protective layer and $\varepsilon_{0}$ is the permittivity of free space.

It was also observed that the \%IE increases as the concentration of the ILs increases reaching a maximum value of $79.88 \%$ for [HMIM] [TfO] at $500 \mathrm{ppm}$. The plot of $\% I E$ values obtained from the electrochemical impedance spectroscopy study versus concentration of inhibitors is shown in Figure 6. The variation of \%IE with concentration shown in Figure 6 is similar to the one presented in Figure 2 for the potentiodynamic polarization experiments. The discussion of the trend of $\% I E$ for the studied ILs presented under Section 2.1.1 therefore applies.

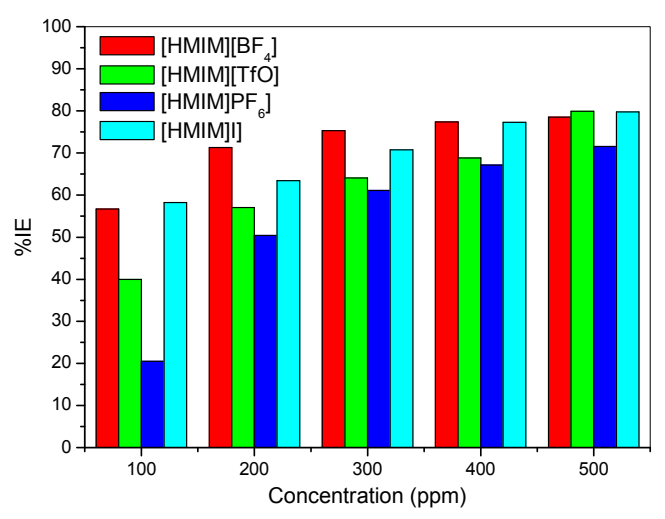

Figure 6. Inhibition Efficiency versus Concentration from the EIS method. 


\subsection{Adsorption Isotherms}

Adsorption isotherms are used to describe the nature of metal/inhibitor interactions. The results obtained from both the polarization and impedance studies were fitted into different adsorption isotherms. Adsorption of [HMIM][BF4], [HMIM][TfO], and [HMIM][I] were found to obey the Langmuir adsorption equation of the form:

$$
\frac{C}{\theta}=C+\frac{1}{K_{a d s}}
$$

where $\mathrm{C}$ is the concentration of the inhibitors, $\theta$ the degree of surface coverage, $K$ ads is the equilibrium constant of the adsorption/desorption process. However, the adsorption of [HMIM][PF6] on mild steel surface followed the Temkin adsorption isotherm equation of the form:

$$
-2 a \theta=\ln K+\ln C
$$

where $\theta$ is surface coverage, $K_{\text {ads }}$ equilibrium constant of adsorption/desorption process, " $a$ " is molecular interaction parameter, and $C$ is the concentration of the inhibitor. The respective adsorption isotherms are shown in Figure 7. The estimated $K_{\text {ads }}$ and change in Gibbs free energy of adsorption ( $\Delta G^{\circ}$ ads) for the four ILs are presented in Table 3. The change in Gibbs free energies $\left(\Delta G^{\circ}\right.$ ads) is related to the $K_{\text {ads }}$ according to the equation:

$$
\Delta G^{o}{ }_{a d s}=-R T \ln \left(55.5 K_{a d s}\right)
$$

where $\Delta G^{\circ}$ ads is the change in Gibbs free energy, $R$ is gas constant, $T$ is absolute temperature, $K_{\text {ads }}$ is the adsorption equilibrium constant and the constant value (55.5) is the molar concentration of water in solution. High values of $K_{\text {ads }}$ and negative values of $\Delta G^{\circ}$ ads obtained for the studied inhibitors as shown in Table 3 imply effective adsorption and spontaneous adsorption of the ILs to mild steel surface. The value of Temkin parameter " $a$ " indicates the repulsive nature of the inhibitor on the metal surface. The negative values obtained for $[\mathrm{HMIM}]\left[\mathrm{PF}_{6}\right]$ in this study suggest possibility of repulsion in the adsorption layer [49]. The magnitude of $\Delta G^{\circ}$ ads determines the nature of adsorption process whether it is physisorption or chemisorption. Values around $-20 \mathrm{~kJ} \cdot \mathrm{moL}^{-1}$ and less are associated with physical adsorption mechanism or physisorption, while values around $-40 \mathrm{~kJ} \cdot \mathrm{moL}^{-1}$ and more are associated with chemical adsorption mechanism or chemisorption [50]. The results in Table 3 show that the magnitudes of $\Delta G^{\circ}$ ads for the four inhibitors are greater than 20 but less than 40 . This suggests that the adsorption process of the studied inhibitors features both physisorption and chemisorption $[17,51,52]$.

Table 3. Adsorption parameters derived from the Langmuir and Temkin adsorption isotherm plots for the inhibitors.

\begin{tabular}{cccc}
\hline Inhibitor & $\mathbf{K}_{\text {ads }}\left(\mathbf{1 0}^{\mathbf{3}} \times \mathbf{~ m o L}^{-\mathbf{1}}\right)$ & Molecular Interaction Parameter $(\mathbf{p p m})$ & $-\Delta G_{\text {ads }}^{\text {o }}\left(\mathbf{k J} \cdot \mathbf{m o L}^{-\mathbf{1}}\right)$ \\
\hline & \multicolumn{3}{c}{ Potentiodynamic Polarization } \\
\hline$[\mathrm{HMIM}]\left[\mathrm{BF}_{4}\right]$ & 4.65 & & -31.41 \\
{$[\mathrm{HMIM}][\mathrm{TfO}]$} & 1.76 & -1.65 & -28.96 \\
{$[\mathrm{HMIM}][\mathrm{I}]$} & 7.37 & 32.56 \\
{$[\mathrm{HMIM}]\left[\mathrm{PF}_{6}\right]$} & 4.55 & 31.35 \\
\hline
\end{tabular}


Table 3. Cont.

\begin{tabular}{cccc}
\hline Inhibitor & $\mathbf{K}_{\text {ads }}\left(\mathbf{1 0}^{\mathbf{3}} \times \mathbf{m o L}^{-\mathbf{1}}\right)$ & Molecular Interaction Parameter $\mathbf{( p p m )}$ & $-\Delta G_{\text {ads }}^{\mathbf{o}}\left(\mathbf{k J} \cdot \mathbf{m o L}^{-\mathbf{1}}\right)$ \\
\hline & \multicolumn{3}{c}{ Impedance } \\
\hline$[\mathrm{HMIM}]\left[\mathrm{BF}_{4}\right]$ & 4.03 & & -31.04 \\
{$[\mathrm{HMIM}][\mathrm{TfO}]$} & 1.73 & -1.58 & -28.92 \\
{$[\mathrm{HMIM}][\mathrm{I}]$} & 3.45 & -30.65 \\
{$[\mathrm{HMIM}]\left[\mathrm{PF}_{6}\right]$} & 6.06 & -32.07 \\
\hline
\end{tabular}
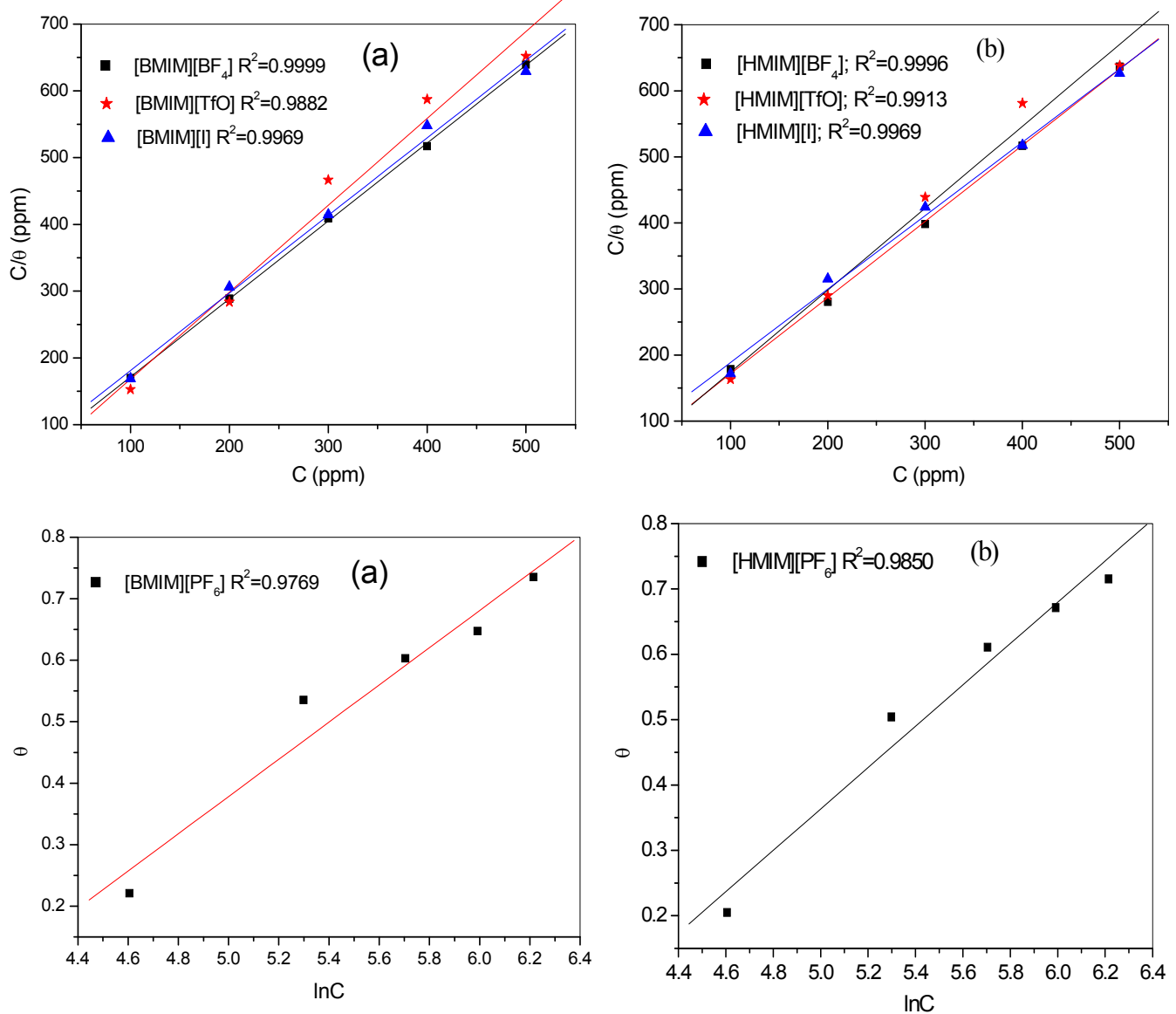

Figure 7. Langmuir adsorption isotherms of [HMIM][BF4], [HMIM][TfO], [HMIM][I] and Temkin adsorption isotherm of $[\mathrm{HMIM}]\left[\mathrm{PF}_{6}\right]$ obtained from (a) polarization and (b) impedance experimental data.

\subsection{Spectroscopic Analysis}

\subsubsection{Fourier Transform Infrared Spectroscopy (FTIR)}

Fourier transform infrared (FTIR) spectroscopy was used to investigate possible chemical interactions between the ILs and mild steel. The FTIR spectra of the pure ILs and the resulting solution after $24 \mathrm{~h}$ of mild steel immersion in $1 \mathrm{M} \mathrm{HCl}$ with $500 \mathrm{ppm}$ ILs were studied and presented in Figure 8. Though reports on vibrational spectra of 1-hexyl-3-methylimidazolium ILs are still scanty compared to the 1-butyl analogues, various vibrational bands characteristic of the imidazole ring in imidazolium-based ILs have been reported in literature [53-58]. These include the bands at $3000-3250 \mathrm{~cm}^{-1}$ for the $\mathrm{C}-\mathrm{H}$ stretching of imidazole ring, those at $750-755 \mathrm{~cm}^{-1}$ for out-of-plane 
bending of imidazole ring, bands at $1500-1620 \mathrm{~cm}^{-1}$ for stretching of the imidazole ring and those at 1020-1050 $\mathrm{cm}^{-1}$ for ring elongation along the N-C stretch [53-58]. Berg et al. (2005) reported the vibrational spectra of 1-hexyl-3-methylimidazolium chloride and 1-hexyl-3-methylimidazolium hexafluorophosphate and their binary mixture in which it was observed that anions have little or no significant effect on the positions of the vibrational bands of the imidazole ring [58]. Some of the observed spectral bands for the pure ILs in the present work and assignments of the bands are listed in Table 4. The $\mathrm{C}-\mathrm{H}$ stretch of imidazole ring was observed at $3163 \mathrm{~cm}^{-1}$ for pure [HMIM] $\left[\mathrm{BF}_{4}\right]$ and $3140 \mathrm{~cm}^{-1}$ for pure [HMIM][I]. This band might have been affected by the strong cation-anion interactions in pure [HMIM][TfO] leading to its absence in the spectrum. The bands for methylene $\left(-\mathrm{CH}_{2}\right)$ stretching were observed at $2939 \mathrm{~cm}^{-1}$ and $2866 \mathrm{~cm}^{-1}$ in [HMIM][BF4], $2946 \mathrm{~cm}^{-1}$ and $2866 \mathrm{~cm}^{-1}$ in [HMIM][TfO] and $2931 \mathrm{~cm}^{-1}$ and $2860 \mathrm{~cm}^{-1}$ in [HMIM][I]. These bands were also reported to appear between 2862-2937 $\mathrm{cm}^{-1}$ in [HMIM] [Cl] and [HMIM][PF 6$]$ according to the work by Berg et al. [58]. Bands for the deformations of the two $-\mathrm{CH}_{3}$ appeared at $1573 \mathrm{~cm}^{-1}$ and $1465 \mathrm{~cm}^{-1}$ (in both pure $[\mathrm{HMIM}]\left[\mathrm{BF}_{4}\right]$ and $[\mathrm{HMIM}][\mathrm{TfO}]$ ), while the same bands appeared respectively at $1567 \mathrm{~cm}^{-1}$ and $1459 \mathrm{~cm}^{-1}$ in pure [HMIM][I]. These bands were also observed between $1442-1570 \mathrm{~cm}^{-1}$ in the work of Berg et al. [58] on pure [HMIM][Cl], [HMIM][PF6] and their binary mixture. In the absence of FTIR spectrum for the pure $\left[\mathrm{HMIM}_{[} \mathrm{PF}_{6}\right]$ in the present work, the FTIR features of $[\mathrm{HMIM}]\left[\mathrm{PF}_{6}\right]$ after mild steel immersion were compared with the vibrational spectrum of pure $[\mathrm{HMIM}]\left[\mathrm{PF}_{6}\right]$ reported by Berg and his co-workers (Table 4) [58]. As shown in Figure 8, all the prominent bands in the pure ILs have disappeared upon mild steel immersion. This is due to the adsorption of the ILs on mild steel surface.
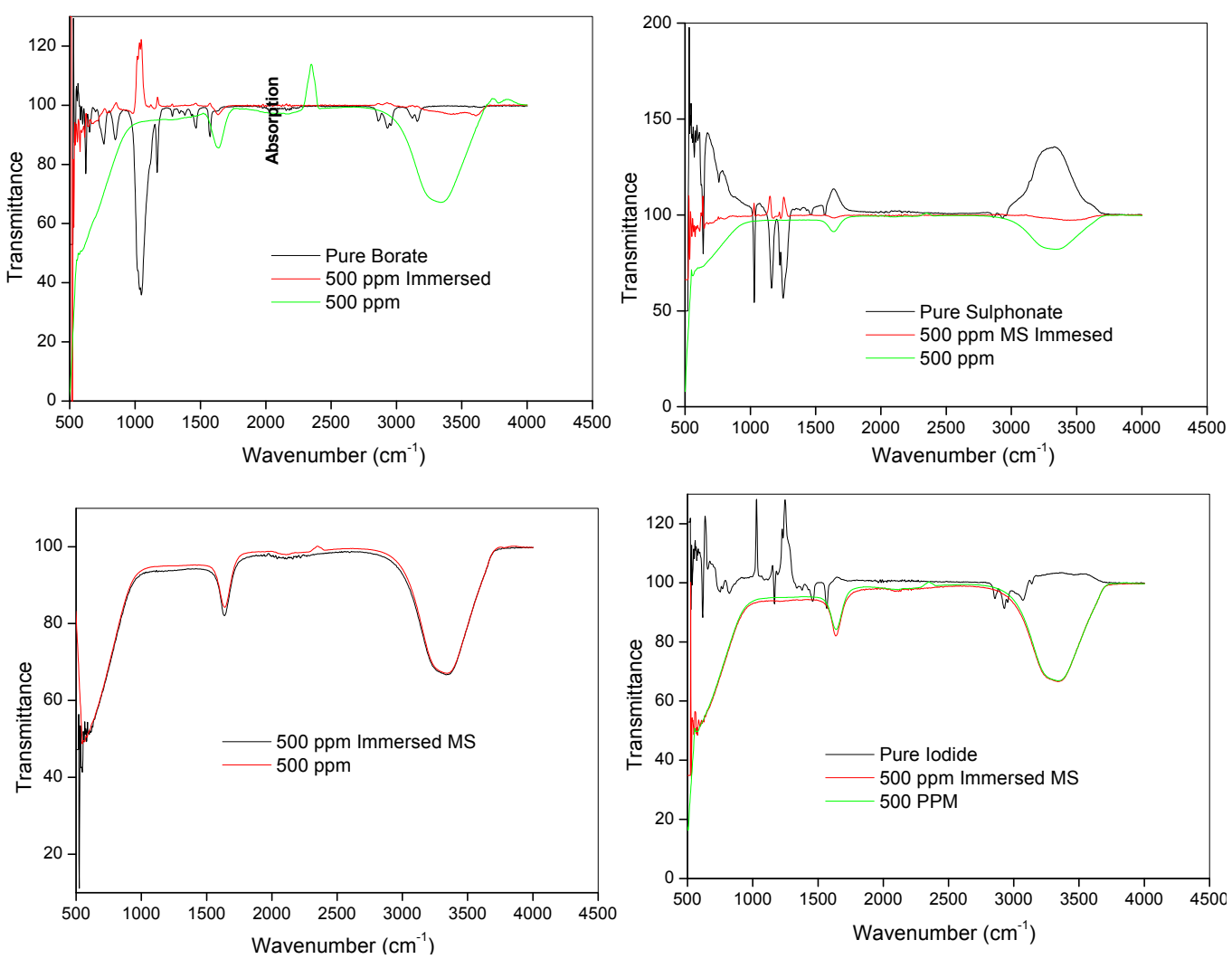

Figure 8. FTIR spectra of pure, $500 \mathrm{ppm}$ solution and $500 \mathrm{ppm}$ with mild steel immersed of the ILs [HMIM][BF4], [HMIM][TfO], [HMIM][I] and [HMIM][PF6]. 
Table 4. Assignment of major vibrational bands in the FTIR spectra of the pure ILs.

\begin{tabular}{|c|c|c|c|c|}
\hline$[\mathrm{HMIM}]\left[\mathrm{BF}_{4}\right]$ & [HMIM][TfO] & [HMIM][I] & {$[\mathrm{HMIM}]\left[\mathrm{PF}_{6}\right]^{\mathrm{a}}$} & Assignments ${ }^{\text {b }}$ \\
\hline 628 & - & 628 & 623 & $\begin{array}{l}\text { ring } \operatorname{def}(\mathrm{C} 2-\mathrm{H} \text { oopl bend })+\mathrm{N}-\mathrm{C} 6 \mathrm{~N}-\mathrm{C} 7 \mathrm{iph} \text { str }+ \\
\qquad \mathrm{C}^{-} \mathrm{H}_{2} \text { rock }+\mathrm{C} 7-\mathrm{C} 8-\mathrm{C} 9 \text { bend }\end{array}$ \\
\hline 657 & 642 & 645 & 658 & $\begin{array}{c}\mathrm{N}-\mathrm{C} 6 \mathrm{str}+\text { ring def }(\mathrm{N} 1 \text { and } \mathrm{H} \text { on } \mathrm{C} 2 \text { oopl ooph } \\
\text { departure })+\mathrm{C} 8 \mathrm{H}_{2} \text { wag }+\mathrm{N}-\mathrm{C} 7-\mathrm{C} 8 \text { bend }+ \text { ring def } \\
\text { (bend around line } \mathrm{NN})+\mathrm{C} 8 \mathrm{H}_{2} \text { rock }+\mathrm{N}-\mathrm{C} 7-\mathrm{C} 8 \text { bend }\end{array}$ \\
\hline 758 & 765 & 751 & 762 & ring $\mathrm{C}-\mathrm{H}$ oopl iph bend (umbrella) \\
\hline 851 & 866 & 823 & 817,852 & $\mathrm{C} \mathrm{H}_{2}$ rock and chain def \\
\hline 1053 & 1032 & - & 1026 & ring elongation $(\mathrm{C} 3)+\mathrm{N}-\mathrm{C} 6 \mathrm{str}$ \\
\hline 1085 & - & - & 1079 & chain ooph C-C str \\
\hline 1170 & 1170 & 1170 & 1169 & chain ooph C-C str \\
\hline- & 1256 & - & 1257 & chain def, $\mathrm{CH}_{2}$ twi \\
\hline 1343 & - & - & 1339 & chain $\left(\mathrm{CH}_{2}\right.$ twi $)$ \\
\hline 1386 & - & 1386 & 1389 & ring breathing $+\mathrm{C} \mathrm{H}_{2}$ twi \\
\hline 1465 & 1465 & 1460 & 1460 & $\mathrm{C} 7 \mathrm{H}_{2}+\mathrm{C} 8 \mathrm{H}_{2}+\mathrm{C} \mathrm{H}_{2}+\mathrm{C} 10 \mathrm{H}_{2}$ def \\
\hline 1573 & 1573 & 1573 & 1570 & $\mathrm{C}_{12} \mathrm{H}_{3} \operatorname{def} \& \mathrm{C}_{6} \mathrm{H}_{3} \operatorname{def}$ \\
\hline 2866 & 2866 & 2860 & 2866 & methylene $\mathrm{CH} 2$ str \\
\hline 2939 & 2946 & 2931 & 2927,2937 & methylene $\mathrm{CH} 2 \mathrm{str}$ \\
\hline- & - & 3069 & 3115 & C-H str. (ring, position 2) \\
\hline 3163 & - & 3140 & 3180 & C-H str. (ring, position 4,5) \\
\hline
\end{tabular}

${ }^{\mathrm{a}}$ data from Ref. [58]. ${ }^{\mathrm{b}}$ abbreviations used for different vibrational modes: bend $=$ angle bending (scissoring), breathing $=$ all ring bonds $\mathrm{iph}, \mathrm{def}=$ more complicated deformation of skeleton, $\mathrm{iph}=$ in phase (symmetric), oopl $=$ out of ring plane, ooph = opposite motion, out of phase (asymmetric), ring $=$ imidazole core, rock $=$ rocking, $\mathrm{str}=$ bond stretching, twi $=$ twisting of $\mathrm{CH}_{2}$ group or chain, wag $=$ wagging.

\subsubsection{Ultraviolet-visible (UV-vis) Spectroscopy}

UV-vis spectroscopy was used to provide evidence of interactions between mild steel and ILs. The UV-vis absorption spectra of the pure ILs, the $500 \mathrm{ppm}$ solution of ILs and the resulting solution after $24 \mathrm{~h}$ of mild steel immersion were recorded and presented in Figure 9. The absorption spectra of the pure ILs show a single shoulder-like absorption peak at $226 \mathrm{~nm}, 225 \mathrm{~nm}$ and $218 \mathrm{~nm}$ for $[\mathrm{HMIM}]\left[\mathrm{BF}_{4}\right],[\mathrm{HMIM}][\mathrm{TfO}]$ and $[\mathrm{HMIM}][\mathrm{I}]$ respectively corresponding to $\mathrm{n}-\pi^{*}$ and/or $\pi-\pi^{*}$ transitions. The UV-vis spectrum of [HMIM][I] also shows additional peak at $245 \mathrm{~nm}$. The absorption spectrum of the pure $[\mathrm{HMIM}]\left[\mathrm{PF}_{6}\right]$ was not reported in this work because it was characterized with a lot of noise, which may be due to impurities or high concentration of the pure [HMIM][PF6]. The $500 \mathrm{ppm}$ solutions of the ILs in $1 \mathrm{M} \mathrm{HCl}$ show absorption characteristics similar to the pure ILs but with generally lower absorbance and slight blue shift in the maximum absorption wavelength to $222 \mathrm{~nm}, 220 \mathrm{~nm}$ and $242 \mathrm{~nm}$ for [HMIM][BF4], [HMIM][TfO] and [HMIM][I] respectively. The absorption spectrum of $500 \mathrm{ppm}$ solution of $[\mathrm{HMIM}]\left[\mathrm{PF}_{6}\right]$ also shows a shoulder-like peak at $220 \mathrm{~nm}$. Upon mild steel immersion, there is a significant change in the UV-vis absorption spectra of the studied ILs as they undergo further blue shift and now appear at $211 \mathrm{~nm}, 210 \mathrm{~nm}, 210 \mathrm{~nm}$ and $222 \mathrm{~nm}$ for $[\mathrm{HMIM}]\left[\mathrm{BF}_{4}\right]$, [HMIM][TfO], $[\mathrm{HMIM}]\left[\mathrm{PF}_{6}\right]$ and $[\mathrm{HMIM}][\mathrm{I}]$ respectively. This blue shift in the wavelength of maximum absorbance is attributed to the formation of Fe/IL complex. Apart from [HMIM][I], the other three ILs show new absorption peak at $248 \mathrm{~nm}$. This new peak can be attributed 
to transition between $\pi$-bonding orbital of the Fe/IL complex and the $\pi^{*}$ (antibonding) orbital of the anion. The absence of this new peak in [HMIM][I] can be due to lack of appropriate $\pi^{*}$-orbital in the iodide ion.
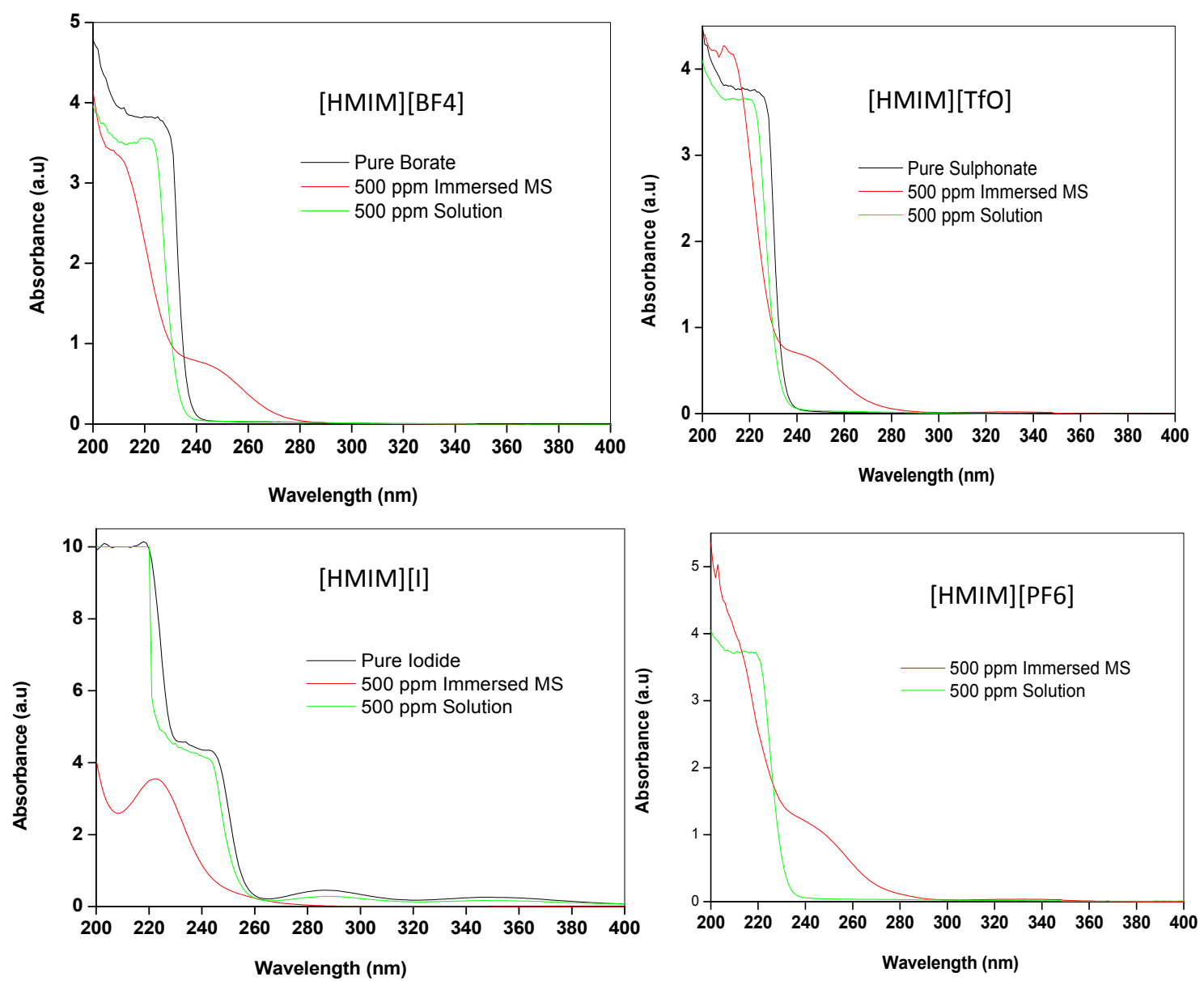

Figure 9. UV/Vis spectra of the pure [HMIM][BF4], [HMIM][TfO], [HMIM][I] and [HMIM][PF6], and their 500 ppm solution without and with mild steel immersed.

\subsubsection{Quantum Chemical Calculations}

Geometry optimizations and quantum chemical calculations were carried out on the studied ILs using the B3LYP/6-31G+(d,p) model. The optimized structures of the ILs are shown in Figure 10. The frontier molecular orbital surfaces provide information about the occupied molecular orbital (HOMO) of the inhibitor that may be responsible for forward donation of a pair of electrons to the vacant d-orbital of the metal and the unoccupied molecular orbital (LUMO) of the inhibitor that may be liable to accept a pair of electrons from an electron-rich metal surface during back-bonding. The HOMO and LUMO graphics of the optimized structures are shown in Figure 11. It can be observed from Figure 11 that the HOMO of [HMIM][I] and [HMIM][TfO] are essentially localized on the corresponding anions; $\mathrm{I}^{-}$and $\mathrm{TfO}^{-}$respectively. This may be due to high polarizability of $\mathrm{I}^{-}$ion and high electron density of $\mathrm{TfO}^{-}$. The HOMO of $[\mathrm{HMIM}]\left[\mathrm{BF}_{4}\right]$ and $[\mathrm{HMIM}]\left[\mathrm{PF}_{6}\right]$ on the other hand are significantly localized on the imidazolium ring and extended along the hexyl side chain as well as to some of the fluorine atoms in the anions. The LUMO surfaces of the four ILs are mainly distributed on the imidazolium ring. This may be due to the presence of highly electronegative nitrogen atoms in the imidazolium ring, which can make the ring to be relatively electron-deficient, and the fact that it is 
a cationic moiety. The numerical values obtained for some of the quantum chemical parameters are listed in Table 5. The results in Table 5 show that [HMIM][I] has the highest value of $E_{\mathrm{HOMO}}$, while [HMIM] $\left[\mathrm{PF}_{6}\right]$ is characterized with the lowest value of $E_{\mathrm{LUMO}}$ among the four ILs. It can be inferred from the $E_{\text {HOMO }}$ results that [HMIM][I] and [HMIM][TfO] have higher electron donating ability than $[\mathrm{HMIM}]\left[\mathrm{BF}_{4}\right]$ and $[\mathrm{HMIM}]\left[\mathrm{PF}_{6}\right]$. [HMIM][I] and [HMIM][TfO] also have lower energy gap $(\Delta E)$ than $[\mathrm{HMIM}]\left[\mathrm{BF}_{4}\right]$ and $[\mathrm{HMIM}]\left[\mathrm{PF}_{6}\right]$. This connotes higher reactivity with mild steel, which is in agreement with their higher percentage inhibition efficiency as observed from polarization experiment. The values of hardness $(\eta)$ and softness $(\sigma)$ also favour better reactivity of [HMIM][I] and [HMIM] [TfO] over $[\mathrm{HMIM}]\left[\mathrm{BF}_{4}\right]$ and $[\mathrm{HMIM}]\left[\mathrm{PF}_{6}\right]$ and hence, better corrosion inhibition ability. Dipole moment does not appear to be a good descriptor of the corrosion inhibition potency of the studied ILs because the values of the dipole moments obtained for the inhibitors are relatively close.

Mulliken population analysis provides information about the amount of charges centred on each atom in a molecule. An atom with large amount of negative charge is expected to be prone to an attack by an electron-deficient species. The estimated Mulliken atomic charges for the studied ILs are displayed alongside the optimized structures in Figure 12. It can be observed from Figure 12 that the I-ion in [HMIM][I], the sulphur and oxygen atoms in [HMIM][TfO], the fluorine atoms in $[\mathrm{HMIM}]\left[\mathrm{BF}_{4}\right]$ and $[\mathrm{HMIM}]\left[\mathrm{PF}_{6}\right]$ all show relatively high negative values of Mulliken atomic charges. This suggests that the metallic atom with a charge-deficient centre will readily be attracted to the appropriate atom in the anionic moiety of the studied ILs.

Table 5. Quantum chemical parameters of the studied ILs.

\begin{tabular}{|c|c|c|c|c|c|c|}
\hline \multirow{2}{*}{ ILs } & \multicolumn{6}{|c|}{ Quantum Chemical Parameters } \\
\hline & Dipole Moment (Debye) & Еномо $(\mathrm{eV})$ & ELumo $(e V)$ & $\Delta E(e V)$ & Hardness $(\eta)$ & Softness $(\sigma)$ \\
\hline [HMIM][I] & 13.36 & -4.53 & -1.36 & 3.17 & 1.58 & 0.63 \\
\hline [HMIM][TfO] & 12.80 & -6.67 & -1.49 & 5.18 & 2.59 & 0.39 \\
\hline$[\mathrm{HMIM}]\left[\mathrm{BF}_{4}\right]$ & 12.58 & -8.24 & -1.37 & 6.87 & 3.44 & 0.29 \\
\hline$[\mathrm{HMIM}]\left[\mathrm{PF}_{6}\right]$ & 14.26 & -8.42 & -1.54 & 6.88 & 3.44 & 0.29 \\
\hline
\end{tabular}

Figure 10. Gas phase optimized structures of [HMIM][BF 4 , [HMIM][TfO], [HMIM][I] and $[\mathrm{HMIM}]\left[\mathrm{PF}_{6}\right]$ at B3LYP/6-31+G(d,p) level of theory. 

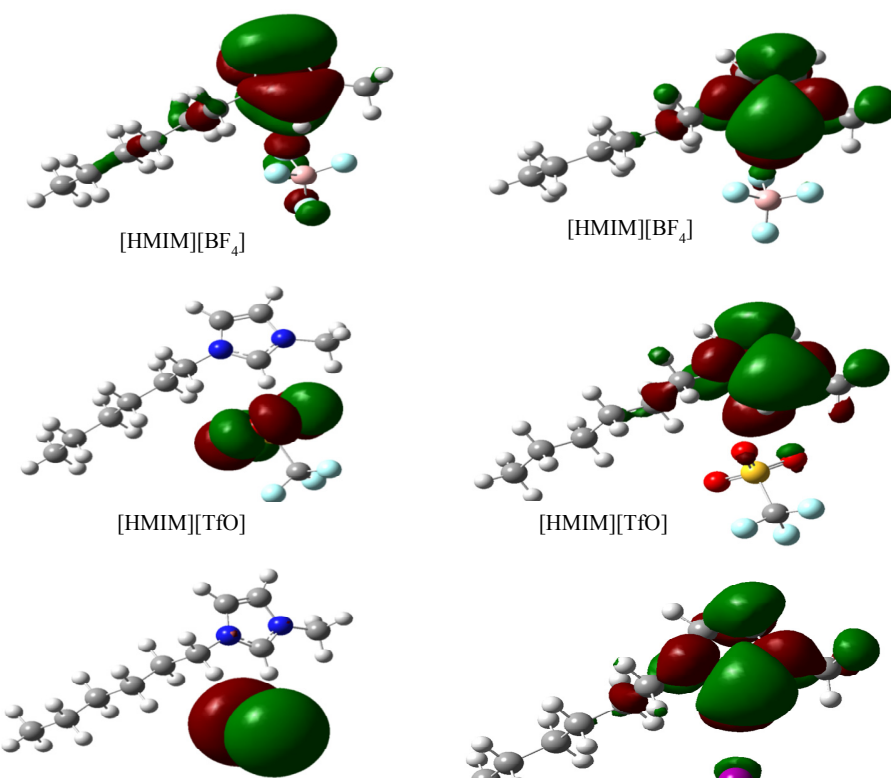

[HMIM][I]
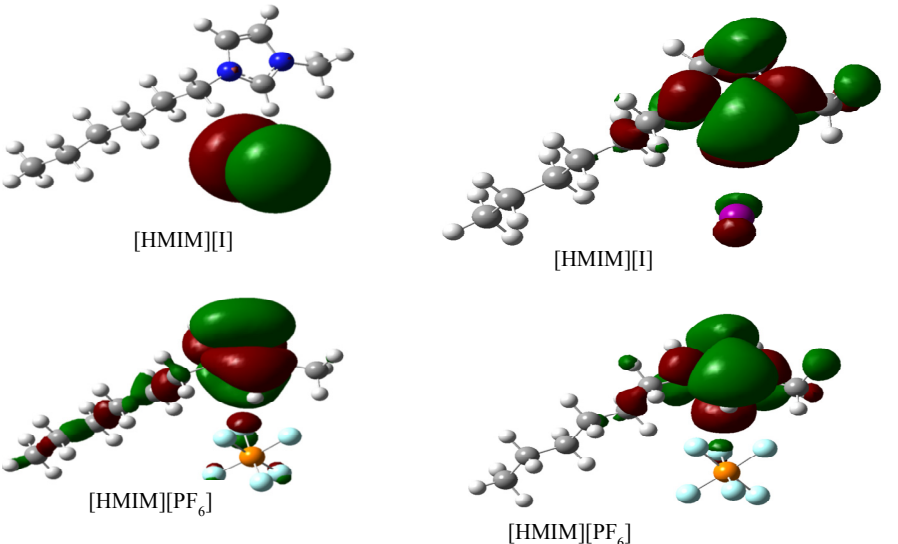

Figure 11. Graphical surfaces of the HOMO (left) and LUMO (right) of the gas phase optimized structures of [HMIM][BF4], [HMIM][TfO], [HMIM][I] and [HMIM][PF6] at $\mathrm{B} 3 \mathrm{LYP} / 6-31 \mathrm{G}+(\mathrm{d}, \mathrm{p})$ level of theory.

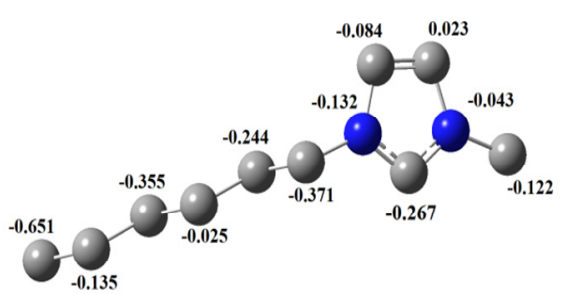

[HMIM][I]

$\overbrace{-0.602}$

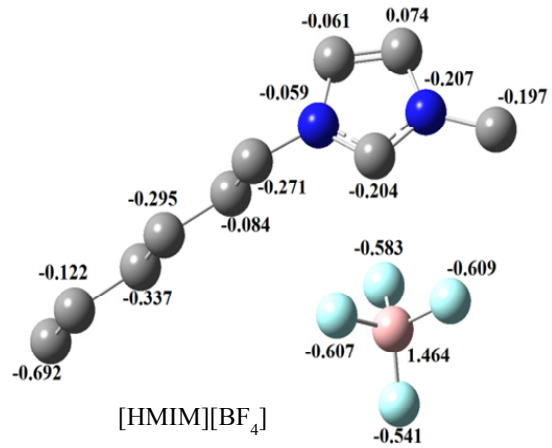

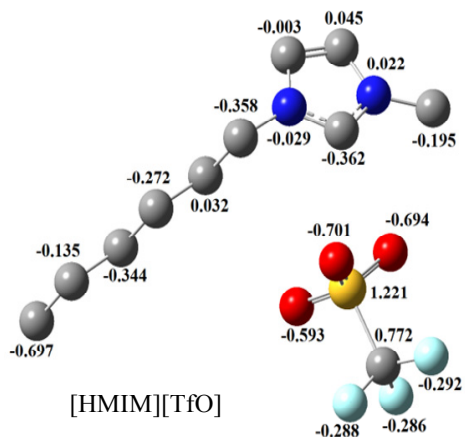

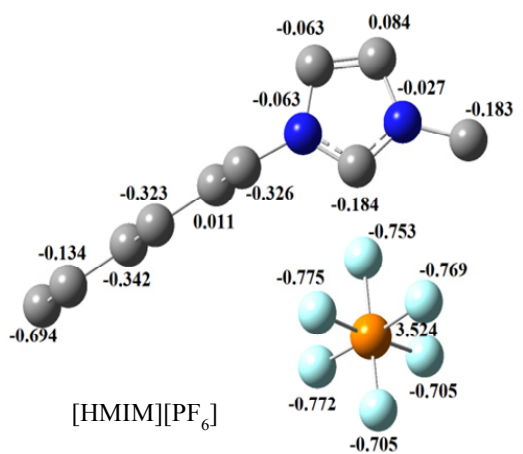

Figure 12. Mulliken atomic charges with optimized structures of [HMIM][BF4], [HMIM][TfO], [HMIM][I] and [HMIM][PF $]$ obtained at B3LYP/6-31+G(d,p) level of theory. 
Fukui indices were also calculated for the studied ILs as a measure of local reactivity. The preferred site for nucleophilic attack is the atom/region in the molecule with the highest value of $f^{+}$while the most probable site for electrophilic attack is the atom/region in the molecule with the highest value of $f^{-}$. The Fukui functions are utilised in the study of corrosion inhibitors to characterize local electron-donating and electron-accepting ability of the inhibitor. Hence, the preferred sites at which the inhibitor is most likely to interact with either an electron-rich or electron-deficient metal surface can be predicted. The results obtained for the $f^{+}$and $f^{-}$are shown in Figure 13. Due to convergence problem, effective core potential was put on the iodide ion in [HMIM][I] using the LanL2DZ basis and 6-31G(d) for other atoms. $6-31+\mathrm{G}(\mathrm{d}, \mathrm{p})$ basis set was used for other ILs. The regions of a molecule where the Fukui function is large are chemically softer than the regions where the Fukui function is small [59]. Fukui function provide information about the atoms in a molecule that have a tendency to either donate (nucleophilic character) or accept (electrophilic character) an electron or pair of electrons [60]. The local selectivity of a corrosion inhibitor is best analysed by means of condensed Fukui function. For all the studied ILs, the preferred sites for nucleophilic attack are the $\mathrm{N}$ and some of the $\mathrm{C}$ atoms, especially $\mathrm{C}-2$ of the imidazolium ring. This is because the imidazolium ring is positively charged and can readily receive charges when attacked by a nucleophilic reagent. The preferred sites for electrophilic attack are essentially on the anions of each IL. As shown in Figure 13, the preferred site for electrophilic attack is the iodide ion for [HMIM][I], the oxygen atoms of the sulfonate for [HMIM][TfO], some of the fluorine atoms of the fluoroborate for [HMIM] $\left.\mathrm{BF}_{4}\right]$ and fluorine atoms of the fluorophosphate for [HMIM] $\left[\mathrm{PF}_{6}\right]$. This is due to high electron density of these atoms, which make it possible for them to donate charge when attacked by an electrophilic reagent.

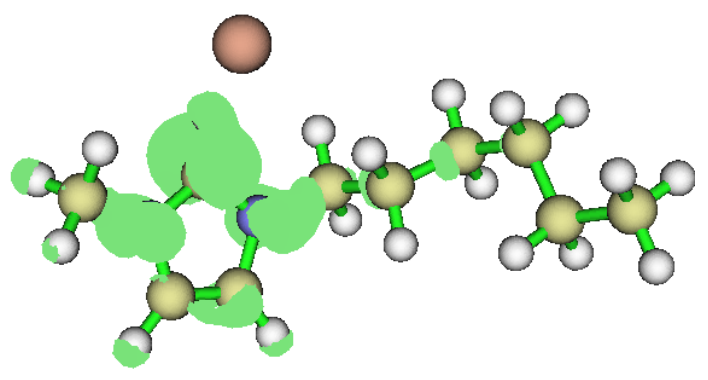

[HMIM]

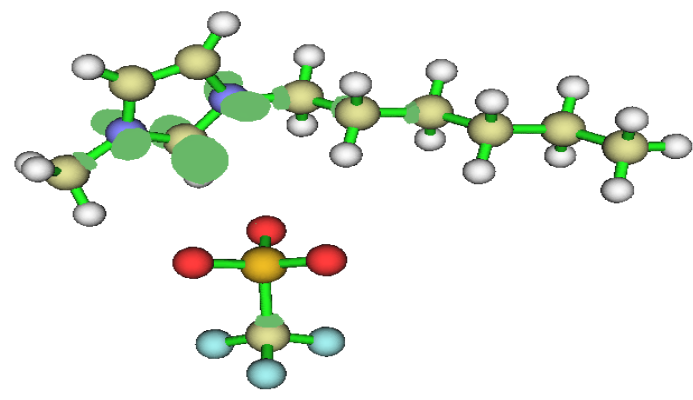

[HMIM]

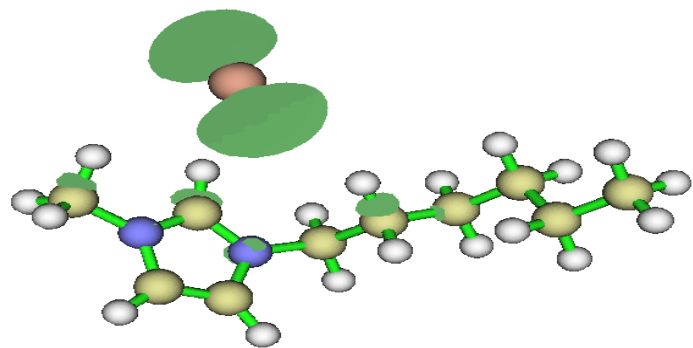

[I]

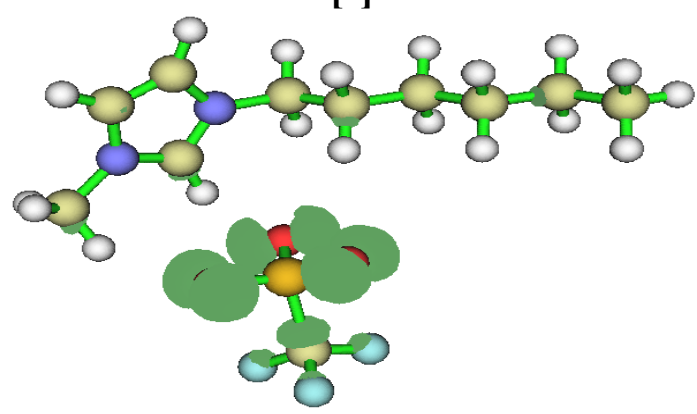

[TfO]

Figure 13. Cont. 


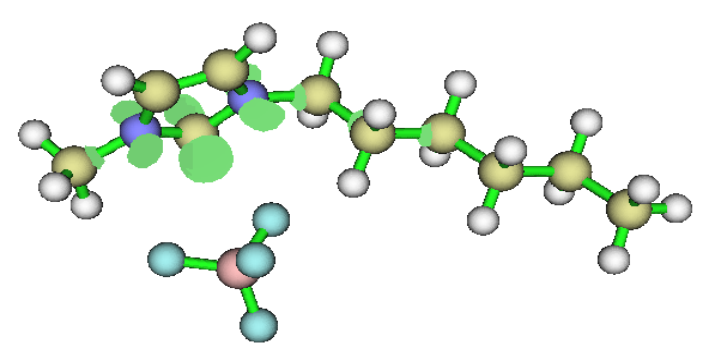

[HMIM]

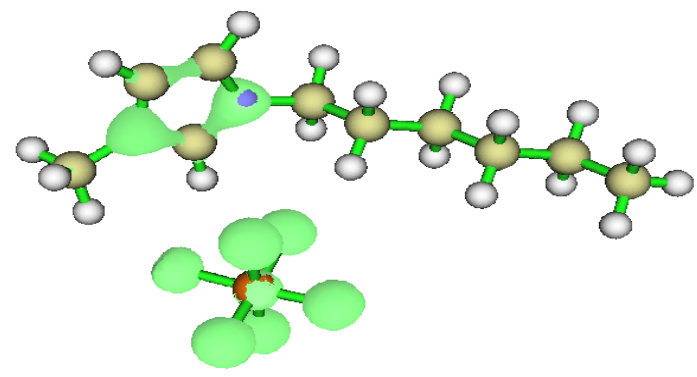

[HMIM]

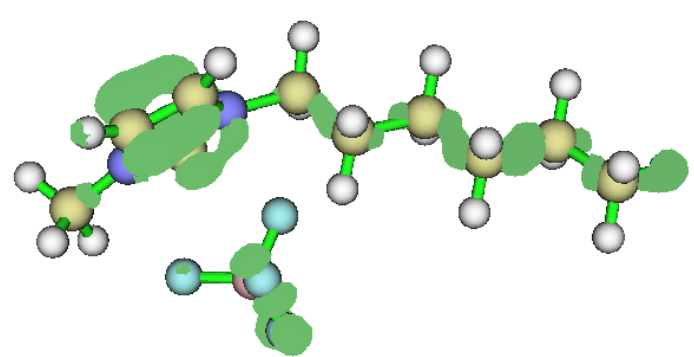

$\left[\mathrm{BF}_{4}\right]$

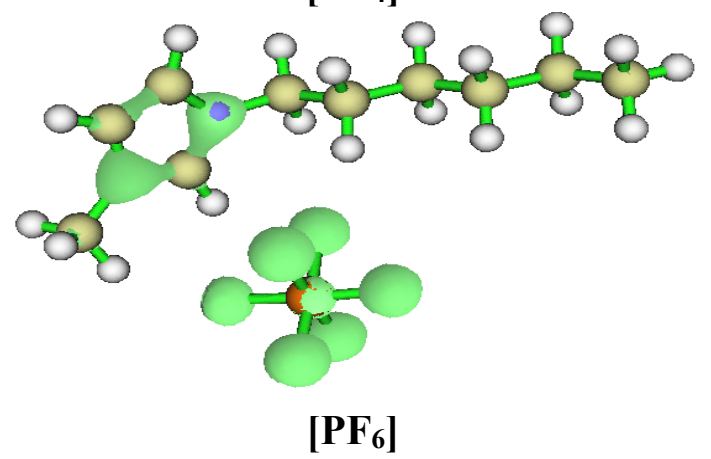

Figure 13. Fukui indices, $f^{+}$(Left) and $f^{-}$(Right) of [HMIM][I] ${ }^{\mathrm{a}, \mathrm{b}}$, [HMIM][TfO] ${ }^{\mathrm{c}}$, [HMIM] $\left[\mathrm{BF}_{4}\right]^{\mathrm{b}}$ and $[\mathrm{HMIM}]\left[\mathrm{PF}_{6}\right]^{\mathrm{c}}{ }^{\mathrm{at}}$ at B $\mathrm{LYP} / 6-31+\mathrm{G}(\mathrm{d}, \mathrm{p}) .{ }^{\mathrm{a}} \mathrm{B} 3 \mathrm{LYP} / 6-31 \mathrm{G}(\mathrm{d}) / / \mathrm{LanL} 2 \mathrm{DZ}$ basis set; ${ }^{\mathrm{b}}$ Isosurface value $=0.04 ;{ }^{\mathrm{c}}$ Isosurface value $=0.3$.

\section{Experimental Section}

\subsection{Materials}

The mild steel sheet used for this work was of the composition 0.02\% Phosphorus (P), $0.37 \%$ Manganese (Mn), 0.03\% Sulphur (S), 0.01\% Molybdenum (Mo), 0.039\% Nickel (Ni), 0.21\% Carbon (C) and the remaining part being iron (Fe). For all electrochemical measurements, mild steel sheet was cut into $1 \mathrm{~cm} \times 1 \mathrm{~cm}$ sizes and embedded in a Teflon holder with epoxy resin thereby exposing a surface area of $1 \mathrm{~cm}^{2}$. Mild steel surface was mechanically abraded and treated to a finely ground surface by polishing it with $\mathrm{SiC}$ papers of $600-1200$ grit sizes. The polished surface was washed with water, degreased with ethanol, rinsed with water again and finally dried with a clean towel paper. Mild steel specimens were used for appropriate studies immediately after surface preparation.

\subsection{Inhibitors}

The ILs used in this study were purchased from Sigma-Aldrich Chemicals. The molecular structures of the ILs 1-Hexyl-3-methylimidazolium trifluoromethanesulfonate [HMIM][TfO], 1-Hexyl-3methylimidazolium tetrafluoroburate [HMIM] $\left[\mathrm{BF}_{4}\right]$, 1-Hexyl-3-methylimidazolium iodide [HMIM][I] and 1-Hexyl-3-methylimidazolium hexafluorophosphate [HMIM][PF6] are shown in Figure 14. 


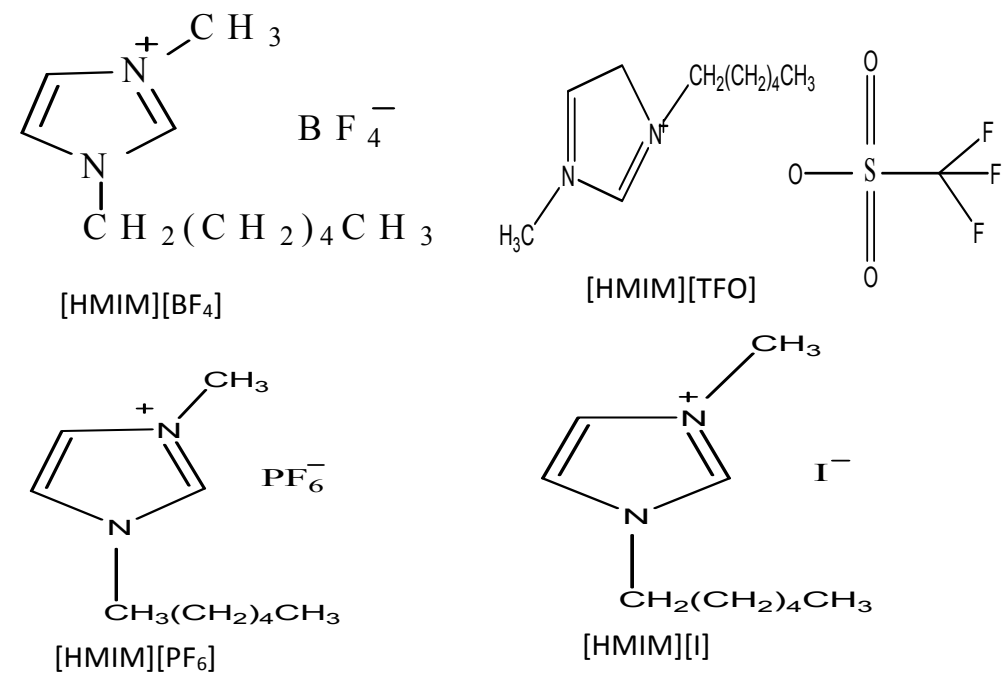

Figure 14. Molecular Structures of 1-Hexyl-3-methylimidazolium hexaflurophosphate ([HMIM][PF6]), Hexyl-3-methylimidazolium trifluoromethanesulfonate ([HMIM][TFO]), 1-Hexyl-3-methylimidazolium iodide ([HMIM][I]) and 1-Hexyl-3-methylimidazolium tetrafluoroborate ([HMIM] $\left.\left[\mathrm{BF}_{4}\right]\right)$.

\subsection{Solutions}

The aggressive solution of $1 \mathrm{M} \mathrm{HCl}$ was prepared by diluting the analytical grade $32 \% \mathrm{HCl}$ from MERCK CHEMICALS with distilled water. The inhibitor concentrations: 100, 200, 300, 400 and 500 ppm were prepared.

\subsection{Electrochemical Measurements}

The electrochemical measurements were performed under unstirred conditions at room temperature $\left(30{ }^{\circ} \mathrm{C}\right)$ using the Autolab (PGSTAT 302N) electrochemical work station from Metrohm driven by the general purpose electrochemical system (GPES) software by Eco Chemie. A stabilization time of $30 \mathrm{~min}$ was allowed before the electrochemical measurements were performed and this time was deemed to be sufficient to attain a stable open circuit potential $(O C P)$. A three-electrode cell composed of a platinum counter electrode (CE), a silver-silver chloride electrode in $3 \mathrm{M} \mathrm{KCl}(\mathrm{Ag} / \mathrm{AgCl}, 3 \mathrm{M} \mathrm{KCl})$ as a reference electrode (RE) and a mild steel specimen of $1 \mathrm{~cm}^{2}$ surface area as a working electrode (WE) was used for all electrochemical measurements. A potential range of -800 to $-200 \mathrm{~V}$ with scan rate $1 \mathrm{mV} \cdot \mathrm{s}^{-1}$ was utilized to generate the potentiodynamic polarization curves. The Tafel slope analysis tool of the GPES software was used to obtain relevant kinetic parameters such as corrosion current density $\left(i_{\text {corr }}\right)$, anodic and cathodic Tafel slopes $\left(\beta_{\mathrm{a}}\right.$ and $\left.\beta_{\mathrm{c}}\right)$ and polarization resistance $(R \mathrm{P})$.

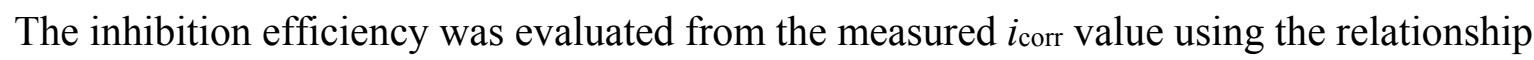

$$
\% I E_{P D P}=100\left(\frac{i_{\text {corr }}^{o}-i_{\text {corr }}^{i}}{i_{\text {corr }}^{o}}\right)
$$

where $i_{\text {corr }}^{o}$ and $i_{\text {corr }}^{i}$ are values of corrosion current density in the absence and presence of inhibitors respectively. 
The EIS measurements were carried out at the frequency range of $100,000.0 \mathrm{~Hz}$ to $1.0 \mathrm{~Hz}$ at an amplitude of $5 \mathrm{mV}$ peak-to-peak using AC signal at the $O C P$. Parameters such as the solution resistance $\left(R_{s}\right)$, the resistance of charge transfer $\left(R_{c t}\right)$ and the capacity of double layer $\left(C_{d l}\right)$ were obtained from the EIS study by fitting the experimental data to the $R_{\mathrm{s}}\left(R_{\mathrm{ct}} Q\right)$ equivalent model circuit using the fit and simulation tool of the GPES software. The inhibition efficiency was calculated using the equation:

$$
\% I E_{E I S}=100\left(1-\frac{R_{c t}^{o}}{R_{c t}}\right)
$$

where $R_{c t}^{o}$ is the charge transfer resistance in the absence of the inhibitor and $R_{c t}$ is the charge transfer resistance in the presence of the inhibitors.

All potentials were measured with reference to that of $\mathrm{Ag} / \mathrm{AgCl}$ in $3 \mathrm{M} \mathrm{KCl}$.

\subsection{Fourier Transform Infrared (FTIR) and Ultraviolet-Visible (UV-Vis) Spectroscopy Experiments}

The FTIR and UV-vis experiments were carried out on the pure ILs and also on the resulting solutions from the aggressive media containing $500 \mathrm{ppm}$ of the studied ILs after $24 \mathrm{~h}$ of mild steel immersion. Fourier transform infrared spectrophotometer (Cary 600 series FTIR spectrometer by Agilent Technology) and the UV-visible spectrophotometer (Cary 300 series UV-vis spectrometer by Agilent Technology) were used for the FTIR and UV-vis studies respectively. Mild steel samples immersed in the aggressive solutions were prepared as explained in Section 3.1 above. The FTIR spectroscopic measurements were recorded between $500-4000 \mathrm{~cm}^{-1}$ wavenumbers, while the UV-vis absorption profiles were recorded between 200-400 $\mathrm{nm}$ wavelengths in the double-beam UV-vis equipment using the $1 \mathrm{~cm}$ quartz cell.

\subsection{Quantum Chemical Calculations}

All geometry optimizations and quantum chemical calculations were performed using the density functional theory (DFT) method. The Becke's three parameter hybrid functional together with the Lee-Yang-Parr correlation functional (B3LYP) [61] and 6-31+G(d,p) basis set were used for the calculations, except when mentioned otherwise. The frontier molecular orbital parameters, i.e., the highest occupied molecular orbital energy $\left(E_{\text {Номо }}\right)$ and the lowest unoccupied molecular orbital energy ( $\left.E_{\mathrm{LUMO}}\right)$ are often used to corroborate observed inhibition potency of corrosion inhibitors. The energy gap $\left(\Delta E, \Delta E=E_{\mathrm{LuMO}}-E_{\mathrm{HOMO}}\right)$ and other chemical reactivity indices including electron affinity $(A)$ and ionization potential $(I)$ are related to the frontier molecular orbital energy parameters according to the Koopman's approximation [62] and also used to explain the observed inhibition potency.

Global hardness $(\eta)$ and softness $(\sigma)$ are molecular properties that also have direct relationship with the molecular reactivity [63]. Soft molecules are more reactive than hard molecules if electron transfer or rearrangement is necessary for the reaction. Hard molecules resist changes in their electron density distribution [64].

$$
\eta \cong-\frac{1}{2}\left(E_{\text {Номо }}-E_{L U M O}\right)
$$




$$
\sigma=\frac{1}{\eta} \cong-\frac{2}{\left(E_{\text {HOMO }}-E_{\text {LUMO }}\right)}
$$

The Fukui function, $f(\mathbf{r})$, is the differential change in electron density due to an infinitesimal change in the number of electrons [65]. The nucleophilic and electrophilic Fukui functions are often used to describe local reactivity condensed on an atom in a molecule. Atom condensed Fukui indices can also be calculated using the finite difference approximation [60]:

$$
\begin{aligned}
& f^{+}=\rho_{(N+1)}-\rho_{N} \\
& f^{-}=\rho_{N}-\rho_{(N-1)}
\end{aligned}
$$

All geometry optimizations were carried out in vacuo using the Gaussian 09 W D (V.01) [66] software. Molecular modelling and initial geometries were generated using the Gaussview 5.0 software. Fukui functions were visualized using Multiwfn software [67,68].

\section{Conclusions}

The following conclusions can be drawn from the results obtained from this study:

- The electrochemical measurements were performed and the inhibition efficiency of the ILs studied was found to be increasing as the inhibitor concentration increased (from $100 \mathrm{ppm}$ to $500 \mathrm{ppm}$ ).

- The $\% I E$ at $500 \mathrm{ppm}$ follows the order $[\mathrm{HMIM}][\mathrm{TfO}]>[\mathrm{HMIM}][\mathrm{I}]>[\mathrm{HMIM}]\left[\mathrm{BF}_{4}\right]>$ $[\mathrm{HMIM}]\left[\mathrm{PF}_{6}\right]$ though the trend of inhibition strength of the studied ILs is not easy to generalize for the range of concentrations of the ILs considered in this work due to the fact that ILs and surfactants are known to undergo self-aggregation and micellization at some characteristic concentrations. Association into aggregates by ILs as well as micelle formation by surfactants are affected by a number of factors, which include alkyl chain, nature of counterions and interactions with water. Since the studied ILs have different anions, they are expected to have different critical aggregate concentration (cac) values, which could have effect on their inhibition ability.

- Mixed-type inhibition mechanism has been proposed for the studied ILs based on the results obtained from the electrochemical studies.

- Three of the ILs, 1-Hexyl-3-methylimidazolium iodide [HMIM][I], 1-Hexyl-3-methylimidazolium tetrafluoroburate $[\mathrm{HMIM}]\left[\mathrm{BF}_{4}\right]$ and 1-Hexyl-3-methylimidazolium trifluoromethanesulfonate [HMIM][TfO] obeyed the Langmuir adsorption isotherm while 1-Hexyl-3-methylimidazolium hexafluorophosphate $[\mathrm{HMIM}]\left[\mathrm{PF}_{6}\right]$ obeyed the Temkin adsorption isotherm.

- Adsorption parameters such as $K_{\text {ads }}$ and $\Delta G^{\circ}$ ads were obtained from the calculations. Results showed that the adsorption process was spontaneous since $\Delta G^{\circ}$ ads value was negative. The range of values of $\Delta G^{\circ}$ ads suggest that the adsorption mechanism of the studied ILs features both physisorption and chemisorption.

- Fourier transform infrared (FTIR) and ultraviolet-visible (UV-vis) spectroscopy studies have been used to support the results obtained from the electrochemical technique.

- Trends in the quantum chemical parameters support the order of inhibition efficiency values obtained from the experimental data. 


\section{Acknowledgments}

M.M.E., L.O.O., A.S.A. and S.Y. acknowledge support from the NRF/Sasol Inzalo foundation for fellowship. A.S.A. and S.Y. also thanks North-West University (NWU) for postdoctoral fellowship. E.E.E. acknowledges financial support from NRF for incentive funding for rated researchers.

\section{Author Contributions}

All the authors have equally contributed to the manuscript.

\section{Conflicts of Interest}

The authors declare no conflict of interest.

\section{References}

1. Olivares-Xometl, O.; Lopez-Aguilar, C.; Herrasti-Gonzalez, P.; Likhanova, N.V.; Lijanova, I.; Martinez-Palou, R.; Rivera-Marquez, J.A. Adsorption and corrosion inhibition performance by three new ILs on API 5L X52 steel surface in acid media. Ind. Eng. Chem. Res. 2014, 53, 9534-9543.

2. De la Fuente, D.; Diaz, I.; Simancas, J.; Chico, B.; Morcillo, M. Long-term atmospheric corrosion of mild steel. Corros. Sci. 2011, 53, 604-617.

3. Ulaeto S.B.; Ekpe U.J.; Chidiebere M.A.; Oguzie E.E. Corrosion inhibition of mild steel in hydrochloric acid by acid extracts of eichhornia crassipes. Int. J. Mater. Chem. 2012, 2, 158-164.

4. Guzman-Lucero D.; Olivares-Xometl O.; Martinez-Palou R.; Likhanova N.V.; Dominguez-Aguilar, M.A.; Garibay-Febles, V. Synthesis of selected vinylimidazolium ils and their effectiveness as corrosion inhibitors for carbon steel in aqueous sulfuric acid. Ind. Eng. Chem. Res. 2011, 50, 7129-7140.

5. Chidiebere, M.A.; Ogukwe, C.E.; Oguzie, K.L.; Eneh, C.N.; Oguzie, E.E. Corrosion inhibition and adsorption behaviour of Punica granatum extract on mild steel in acidic environments: Experimental and theoretical studies. Ind. Eng. Chem. Res. 2012, 51, 668-677.

6. Popova, A.; Sokolova, E.; Raicheva, S.; Christov, M. AC and DC study of the temperature effect on mild steel corrosion in acid media in the presence of benzimidazole derivatives. Corros. Sci. 2003, 45, 33-58.

7. Ebenso, E.E.; Ibok, U.J.; Ekpe, U.J.; Umoren, S.A.; Jackson, E.; Abiola, O.K.; Oforka, N.C.; Martinez, S. Corrosion inhibition studies of some plant extracts on aluminium in acidic medium. Trans. SAEST 2004, 39, 117-123.

8. Daoud, D.; Douadi, T.; Issaadi, S.; Chafaa, S. Adsorption and corrosion inhibition of new synthesized thiophene Schiff base on mild steel $\mathrm{X} 52$ in $\mathrm{HCl}$ and $\mathrm{H}_{2} \mathrm{SO}_{4}$ solutions. Corros. Sci. 2014, 79, 50-58.

9. Al-Amiery, A.A.; Kadhum, A.A.H.; Alobaidy, A.H.M.; Mohamad, A.B.; Hoon, P.S. Novel corrosion inhibitor for mild steel in HCl. Materials 2014, 7, 662-672.

10. Mendes, J.O.; da Silva, E.C.; Rocha, A.B. On the nature of inhibition performance of imidazole on iron surface. Corros. Sci. 2012, 57, 254-259. 
11. Ebenso, E.E.; Obot, I.B. Inhibitive Properties, Thermodynamic characterization and quantum chemical studies of secnidazole on mild steel corrosion in acidic medium. Int. J. Electrochem. Sci. 2010, 5, 2012-2035.

12. Paul, S.; Kar, B. Mitigation of mild steel corrosion in acid by green inhibitors: Yeast, pepper, garlic, and coffee. ISRN Corros. 2012, doi:10.5402/2012/641386.

13. Matad, P.B.; Mokshanatha, P.B.; Hebbar, N.; Venkatesha, V.T.; Tandon, H.C. Ketosulfone drug as a green corrosion inhibitor for mild steel in acidic medium. Ind. Eng. Chem. Res. 2014, 53, 8436-8444.

14. Shivakumar, S.S.; Mohana, K.N. Centella asiatica extracts as green corrosion inhibitor for mild steel in 0.5 M sulphuric acid medium. Adv. Appl. Sci. Res. 2012, 3, 3097-3106.

15. Rajendran, S.; Sri, V.G.; Arockiaselvi, J.; Amalraj, A.J. Corrosion inhibition by plant extracts: An overview. Bull. Electrochem. 2005, 21, 367-377.

16. Lame, A.; Kokalari, E.; Jano, A. Use of green inhibitors for concrete armor protection against $\mathrm{H}_{2} \mathrm{SO}_{4}$ corrosion. Asian J. Chem. 2013, 25, 4017-4021.

17. Likhanova, N.V.; Olivares-Xomet, O.; Guzmán-Lucero, D.; Domínguez-Aguilar, M.A.; Nava, N.; Corrales-Luna, M.; Mendoza, M.C. Corrosion inhibition of carbon steel in acidic environment by imidazolium ILs containing vinyl-hexafluorophosphate as anion. Int. J. Electrochem. Sci. 2011, 6, 4514-4536.

18. Ibrahim, M.A.M.; Messali, M.; Moussa, Z.; Alzahrani, A.Y.; Alamry, S.N.; Hammouti, B. Corrosion inhibition of carbon steel by imidazolium and pyridinium cations ILs in acidic environment. Port. Electrochim. Acta 2011, 29, 375-389.

19. Zhang, Q.B.; Hua, Y.X. Corrosion inhibition of mild steel by alkylimidazolium ILs in hydrochloric acid. Electrochim. Acta 2009, 54, 1881-1887.

20. Acidi, A.; Hasib-ur-Rahman, M.; Larachi, F.; Abbaci, A. Ionic liquids [EMIM][BF4], [EMIM][Otf] and [BMIM][Otf] as corrosion inhibitors for $\mathrm{CO}_{2}$ capture applications. Korean J. Chem. Eng. 2014, 31, 1043-1048.

21. Uerdingen, M.; Treber, C.; Balser, M.; Schmitt, G.; Werner, C. Corrosion behaviour of ionic liquids. Gr. Chem. 2005, 7, 321-325.

22. Murulana, L.C.; Singh, A.K.; Shukla, S.K.; Kabanda, M.M.; Ebenso, E.E. Experimental and quantum chemical studies of some bis(trifluoromethyl-sulfonyl) imide imidazolium-based ILs as corrosion inhibitors for mild steel in hydrochloric acid solution. Ind. Eng. Chem. Res. 2012, 51, 13282-13299.

23. Lozano, I.; Mazario, E.; Olivares-Xometl, C.O.; Likhanova, N.V.; Herrasti, P. Corrosion behaviour of API 5LX52 steel in $\mathrm{HCl}$ and $\mathrm{H}_{2} \mathrm{SO}_{4}$ media in the presence of 1,3-dibencilimidazolio acetate and 1,3-dibencilimidazolio dodecanoate ILs as inhibitors. Mater. Chem. Phys. 2014, 147, 191-197.

24. Wasserscheid, P.; Keim, W. ILs-New "solutions" for transition metal catalysis. Angew. Chem. Int. Ed. 2000, 39, 3772-3789.

25. Torralba-Calleja, E.; Skinner, J.; Gutierrez-Tauste, D. $\mathrm{CO}_{2}$ capture in ILs: A review of solubilities and experimental methods. $J$. Chem. 2013, doi:10.1155/2013/473584.

26. Gordon, C.M. New developments in catalysis using ILs. Appl. Catal. A 2001, 222, 101-117.

27. Holbrey, J.D. Industrial applications of ILs. Chim. Oggi. 2004, 22, 35-37. 
28. Ashassi-Sorkhabi, H.; Es'haghi, M. Corrosion inhibition of mild steel in acidic media by [BMIm]Br ionic liquid. Mater. Chem. Phys. 2009, 114, 267-271.

29. Zhang, Q.B.; Hua, Y.X. Corrosion inhibition of aluminum in hydrochloric acid solution by alkylimidazolium ILs. Mater. Chem. Phys. 2010, 119, 57-64.

30. Zarrouk, A.; Messali, M.; Zarrok, H.; Salghi, R.; Ali, A.A.; Hammouti, B.; Al-Deyab, S.S.; Bentiss, F. Synthesis, characterization and comparative study of new functionalized imidazolium-based ionic liquids derivatives towards corrosion of C38 steel in molar hydrochloric acid. Int. J. Electrochem. Sci. 2012, 7, 6998-7015.

31. Likhanova, N.V.; Domínguez-Aguilara, M.A.; Olivares-Xometl, O.; Nava-Entzanaa, N.; Arcec, E.; Dorantes, H. The effect of ILs with imidazolium and pyridinium cations on the corrosion inhibition of mild steel in acidic environment. Corros. Sci. 2010, 52, 2088-2097.

32. Mahdavian, M.; Attar, M.M. Electrochemical behaviour of some transition metal acetylacetonate complexes as corrosion inhibitors for mild steel. Corros. Sci. 2009, 51, 409-414.

33. Abdel-Gaber, A.M.; Masoud, M.S.; Khalil, E.A.; Shehata, E.E. Electrochemical study on the effect of Schiff base and its cobalt complex on the acid corrosion of steel. Corros. Sci. 2009, 51, 3021-3024.

34. Abdallah, M.; Asghar, B.H.; Zaafarany, I.; Fouda, A.S. The inhibition of carbon steel corrosion in hydrochloric acid solution using some phenolic compounds. Int. J. Electrochem. Sci. 2012, 7, 282-304.

35. Omar, A.; El Seoud, O.A.; Pires, P.A.R.; Abdel-Moghny, T.; Bastos, E.L. Synthesis and micellar properties of surface-active ionic liquids: 1-Alkyl-3-methylimidazolium chlorides. J. Colloid Interface Sci. 2007, 313, 296-304.

36. Singh, T.; Kumar, A. Aggregation behavior of ionic liquids in aqueous solutions: Effect of alkyl chain length, cations, and anions. J. Phys. Chem. B 2007, 111, 7843-7851.

37. Wang, H.; Wang, J.; Zhang, S.; Xuan, X. Structural effects of anions and cations on the aggregation behavior of ionic liquids in aqueous solutions. J. Phys. Chem. B 2008, 112, 16682-16689.

38. Malik, M.A.; Hashim, M.A.; Nabi, F.; AL-Thabaiti, S.A.; Khan, Z. Anti-corrosion ability of surfactants: A review. Int. J. Electrochem. Sci. 2011, 6, 1927-1948.

39. Fuchs-Godec, R. The adsorption, CMC determination and corrosion inhibition of some N-alkyl quaternary ammonium salts on carbon steel surface in $2 \mathrm{M} \mathrm{H}_{2} \mathrm{SO}_{4}$. Colloids Surf. A 2006, 280, $130-139$.

40. Negm, N.A.; Elkholy, Y.M.; Zahran, M.K.; Tawfik, S.M. Corrosion inhibition efficiency and surface activity of benzothiazol-3-ium cationic Schiff base derivatives in hydrochloric acid. Corros. Sci. 2010, 52, 3523-3536.

41. Negm, N.A.; Mohamed, A.S. Surface and thermodynamic properties of diquaternary Bola-form amphiphiles containing an aromatic spacer. J. Surfactant Deterg. 2004, 7, 23-30.

42. Negm, N.A.; Ismail, A.; Aiad, I.A. Synthesis and characterization of multifunctional surfactants in oil-field protection applications. J. Surfactant Deterg. 2007, 10, 87-92.

43. Maayta, A.K.; Al-Rawashdeh, N.A.F. Inhibiton of acidic corrosion of pure aluminium by some organic compounds by some organic compounds. Corros. Sci. 2004, 46, 1129-1140.

44. Martinez, S.; Huksovic, M.M. A nonlinear kinetic model introduced for the corrosion inhibitive properties of some organic inhibitors. J. Appl. Elecrochem. 2003, 33, 1137. 
45. Caprani, A.; Epelboin, I.; Morel, P.; Takenouti, H. Proceedings of the 4th European Symposium on Corrosion Inhibitors; Università degli studi di Ferrara: Ferrara, Italy, 1975; p. 571.

46. Bessone, J.; Meyer, C.; Tuttner, K.; Lorenz, W.J. AC-impedance measurements on aluminium, barrier type oxide films. Electrochim. Acta 1983, 28, 171-175.

47. Singh, A.K.; Shukla, A.K.; Quraishi, M.A.; Ebenso, E.E. Investigation of adsorption characteristics of N,N'-[(methylimino)dimethylidyne] di-2,4-xylidine as corrosion inhibitor at mild steel/sulfuric acid interface. J. Taiwan Inst. Chem. Eng. 2012, 43, 463-472.

48. McCafferty, E.; Hackerman, N. Double layer capacitance of iron and corrosion inhibition with polymethylene diamines. J. Electrochem. Soc. 1972, 119, 146-154.

49. Tang, L.; Li, X.; Si, Y.; Liu, G. The synergistic inhibition between 8-hydroxyquinoline and chloride ion for the corrosion of cold rolled steel in $0.5 \mathrm{M}$ sulfuric acid. Mater. Chem. Phys. 2006, 95, 29-38.

50. Tarik Attar, T.; Larabi, L.; Harek, Y. Inhibition effect of potassium iodide on the corrosion of carbon steel (XC 38) in acidic medium. Int. J. Adv. Chem. 2014, 2, 139-142.

51. Obot, I.B.; Ebenso, E.E.; Obi-Egbedi, N.O.; Afolabi, A.S.; Gasem, Z.M. Experimental and theoretical investigations of adsorption characteristics of itraconazole as green corrosion inhibitor at a mild steel/hydrochloric acid interface. Res. Chem. Intermed. 2012, 38, 1761-1779.

52. Onen, A.I.; Nwufo, B.T.; Ebenso, E.E.; Hlophe, R.M. Titanium (IV) oxide as corrosion inhibitor for aluminium and mild steel in acidic medium. Int. J. Electrochem. Sci. 2010, 5, 1563-1573.

53. Rajkumar, T.; Rao, G.R. Synthesis and characterization of hybrid molecular material prepared by ionic liquid and silicotungstic acid. Mater. Chem. Phys. 2008, 112, 853-857.

54. Rajkumar, T.; Rao, G.R. Investigation of hybrid molecular material prepared by ionic liquid and polyoxometalate anion. J. Chem. Sci. 2008, 120, 587-594.

55. Vyas, S.; Dreyer, C.; Slingsby, J.; Bicknase, D.; Porter, J.M.; Maupin, C.M. Electronic structure and spectroscopic analysis of 1-ethyl-3-methylimidazolium bis(trifluoromethylsulfonyl)imide ion pair. J. Phys. Chem. A 2014, 118, 6873-6882.

56. Wu, W.; Li, W.; Han, B.; Zhang, Z.; Jiang, T.; Liu, Z. A green and effective method to synthesize ionic liquids: Supercritical $\mathrm{CO}_{2}$ route. Green Chem. 2005, 7, 701-704.

57. Lateef, H.; Gooding, A.; Grimes, S. Use of 1-hexyl-3-methylimidazolium bromide ionic liquid in the recovery of lactic acid from wine. J. Chem. Technol. Biotechnol. 2012, 87, 1066-1073.

58. Berg, R.W.; Deetlefs, M.; Seddon, K.R.; Shim, I.; Thompson, J.M. Raman and ab initio studies of simple and binary 1-Alkyl-3-methylimidazolium ionic liquids. J. Phys. Chem. B 2005, 109, 19018-19025.

59. Liao, X.-Y.; Cao, D.-B.; Wang, S.-G.; Ma, Z.-Y.; Li, Y.-W.; Wang, J.; Jiao, H. Density functional theory study of CO adsorption on the (100), (001) and (010) surfaces of FesC. J. Mol. Catal. 2007, 269, 169-178.

60. Fuentealba, P.; Perez, P.; Contreras, R. On the condensed Fukui function. J. Chem. Phys. 2000, 113, 2544-2552.

61. Becke, A.D. Density-functional thermochemistry. III. The role of exact exchange. J. Chem. Phys. 1993, 98, 5648-5652.

62. Senet, P. Chemical hardnesses of atoms and molecules from frontier orbitals. Chem. Phys. Lett. 1997, 275, 527-532. 
63. Ebenso, E.E.; Kabanda, M.M.; Murulana, L.C.; Singh, A.K.; Shukla, S.K. Electrochemical and quantum chemical investigation of some azine and thiazine dyes as potential corrosion inhibitors for mild steel in hydrochloric acid solution. Ind. Eng. Chem. Res. 2012, 51, 12940-12958.

64. Knag, M.; Bilkova, K.; Gulbrandsen, E.; Carlsen, P.; Sjöblom, J. Langmuir-Blodgett films of dococyltriethylammonium bromide and octadecanol on iron deposition and corrosion inhibitor performance in CO2 containing brine. Corros. Sci. 2006, 48, 2592-2613.

65. Li, X.; Deng, S.; Li, H.T. Adsorption and inhibition effect of 6-benzylaminopurine on cold rolled steel in $1.0 \mathrm{M} \mathrm{HCl}$. Electrochim. Acta 2009, 54, 4089-4098.

66. Frisch, M.J.; Trucks, G.W.; Schlegel, H.B.; Scuseria, G.E.; Robb, M.A.; Cheeseman, J.R.; Scalmani, G.; Barone, V.; Mennucci, B.; Petersson, G.A.; et al. Gaussian 09, Revision D.01; Gaussian, Inc.: Wallingford, CT, USA, 2009.

67. Lu, T.; Chen, F. Multiwfn: A multifunctional wavefunction analyzer. J. Comp. Chem. 2012, 33, $580-592$.

68. Lu, T.; Chen, F. Quantitative analysis of molecular surface based on improved Marching Tetrahedra algorithm. J. Mol. Graph. Model. 2012, 38, 314-323.

(C) 2015 by the authors; licensee MDPI, Basel, Switzerland. This article is an open access article distributed under the terms and conditions of the Creative Commons Attribution license (http://creativecommons.org/licenses/by/4.0/). 